\title{
SÍNTESE SOBRE O METAMORFISMO DA REGIÃO GRANULÍTICA DO SUL DA BAHIA - BRASIL
}

\author{
JOHILDO S.F. BARBOSA * \& MICHEL FONTEILLES **
}

\begin{abstract}
SYNTHESIS ABOUT THE METAMORPHISM OF THE GRANULITIC REGION IN THE SOUTH OF BAHIA STATE, BRAZIL. Researches in the granulitic region of southern Bahia, with ages from Archean to lower Proterozoic, have shown a progressive regional metamorphism with a peak of $830^{\circ} \mathrm{C}$ and 6 kbars. It caused a uniform reequilibration in the granulite facies of intrusives and supracrustals rocks of the NW and SE Domains of the Region. In the Central Domain, rocks of the amphibolite, remained essentially unaffected. Where the liquidus pressure was compatible migmatization in the granulite and amphibolite facies has occured. The temperature decrease during late deformation stages/phases, related to the uplift of this deep crustal segment, caused the a appearence of retrograde assembly in the granulite, amphibolite and greenschist facies.
\end{abstract}

Keywords: Granulite facies, amphibolite facies, migmatizated and unmigmatizated zones, Archean/Lower Proterozoic, geothermometry, geobarometry.

\begin{abstract}
RESUMO Na região granulítica do sul da Bahia, de idade arqueana/proterozóica inferior, as pesquisas têm demonstrado a existência de um metamorfismo regional progressivo que atingiu seu clímax em tomo de $830^{\circ} \mathrm{C}$ e $6 \mathrm{kbar}$. Este reequilibrou uniformemente, na fácies granulito, as rochas plutônicas e vulcanossedimentares dos domínios NW e $\mathrm{SE}$ deixando preservada na fácies anfíbolito as rochas do Domínio Central. Tanto na fácies granulito quanto na anfibolito ocorreu migmatização, nos locais onde a pressão de fluidos foi compatível. Com o levantamento deste segmento crustal profundo, o abaixamento das temperaturas, acompanhado da fases de deformações tardias, promove o aparecimento de assembléias retrógradas, não só da fácies granulito mas também das fácies anfíbolito e xisto verde.
\end{abstract}

Palavras-chaves: Fácies granulito, fácies anfíbolito, zonas migmatizadas e não-migmatizadas, Arqueano/Proterozóico Inferior, geotermometria, geobarometria.

INTRODUÇÃO A crosta profunda granulítica, de idade arqueana/proterozóica inferior, do sul do Estado da Bahia, vem sendo estudada desde o início da década de 70 . De lá até hoje, importantes trabalhos têm sido realizados, os quais têm contribuído bastante para o avanço dos conhecimentos geológicos da região. Entre eles pode-se citar os de Sighinolfi (1970, 1971), Cordani (1973), Seixas et al (1975), Sighinolfi \& Sakai (1977), Cordani \& Iyer 1979, Brito Neves et al (1980), Sighinolfi et al (1981), Costa \& Mascarenhas (1982), Lima et al (1982), Oliveira \& Lima (1982), Oliveira et al (1982), Miranda et al (1982), Iyer et al (1984), Delhal \& Demaife (1985), Miranda et al (1985), Iyer et al (1987), Wilson (1987), Wilson et al (1988), Filho (1988) e Cruz (1989).

Uma análise dessas pesquisas permite concluir que, nas áreas específicas onde elas se desenvolveram, conseguira-se informações significativas, principalmente aquelas ligadas à petrografia desses metamorfitos de alto grau, às fases de deformações tectônicas que atuaram nessas áreas e, sobretudo, aquelas relacionadas com as idades das rochas.

Entretanto, com relação ao conhecimento da evolucão do metamorfismo, houve pouca contribuição, sendo os trabalhos mais relevantes os de Oliveira \& Lima (1982), Oliveira et al (1982), Sampaio (1988), que chegaram a estimar as condições de temperatura e pressão do metamorfismo granulítico, por comparação, entre as paragêneses e/ou reações metamórficas identificadas petrograficamente nas rochas, com aquelas produzidas por trabalhos experimentais de laboratório. Faltaram dados quantitativos sobre as condições físicas e químicas que governaram o principal ciclo termo-tectônico da região.

Estudos termodinâmicos de equilíbrio entre fases minerais e cálculos barométricos e termométricos foram realizados pela primeira vez por Barbosa (1986), quando então se chegou a valores quantitativos sobre as condiçôes físicas regionais de $\mathrm{Te}$ $\mathrm{P}$ que presidiram o principal ciclo metamórfico da área. Estes resultados foram aprimorados posteriormente nos trabalhos de Barbosa \& Fonteilles (1986), Barbosa (1988), Xavier et al (1989), Barbosa (1989,1990,1991), Arcanjo et al (no prelo). Este artigo é um resumo da geologia e dos dados metamórficos conseguidos até então na região, tendo por base, sobretudo, as pesquisas desses últimos autores.

ESBOÇO GEOLÓGICO REGIONAL Na região em foco verifica-se, a noroeste, um predomínio de rochas plutõnicas, embora ocorram também rochas supracrustais, todas equilibradas na fácies granulito; a sudeste são encontradas rochas vulcânicas/plutônicas metamorfizadas na fácies granulito; e, na parte central, litologias essencialmente supracrustais, metamorfizadas na fácies anfíbolito (Fig. 1). A seguir são descritas as rochas que compõem estes domínios.

Rochas plutõnicas reequilibradas na fácies granulito (Domínio NW) As rochas enderbíticas, charnoenderbíticas e charnockíticas ocupam a maior porção da região noroeste (Fig. 1). Essas rochas, de uma maneira geral, estão intensamente deformadas por, no mínimo, três fases de deformação dúctil (Costa \& Mascarenhas 1982, Barbosa 1986, 1990), mas auida contêm grandes fenocristais remanescentes de mesopertita e/ou feldspato potássico pertítico, em uma matriz granoblástica de quartzo, plagioclásio antipertítico, ortopiroxênio e quantidades menores de clinopiroxênio, hornblenda marrom e biotita. Os enderbitos têm mineralogia semelhante aos charnockitos, entretanto são mais ricos em plagioclásio e clinopiroxênio (Tab. 1). Essas rochas são geralmente bandadas, com alternância de bandas centimétricas de coloração verde-clara onde predominam feldspatos e bandas verdes escuras de minerais ferromagnesianos abundantes. $\mathrm{O}$ caráter plutônico dessas rochas é reforçado não só pela presença de microcristais de hornblenda isomórfica rica em cloro e de

\footnotetext{
*Instituto de Geociências, Universidade Federal da Bahia. Rua Caetano Moura, 123, Federação, Salvador, CEP 40210-340, São Paulo, SP

**Laboratoire de Geologic Apliquée, Université Pierre et Marie Curie, 4, Place Jussieu, Tour 26, Seme stege, 75252, Paris, França
} 


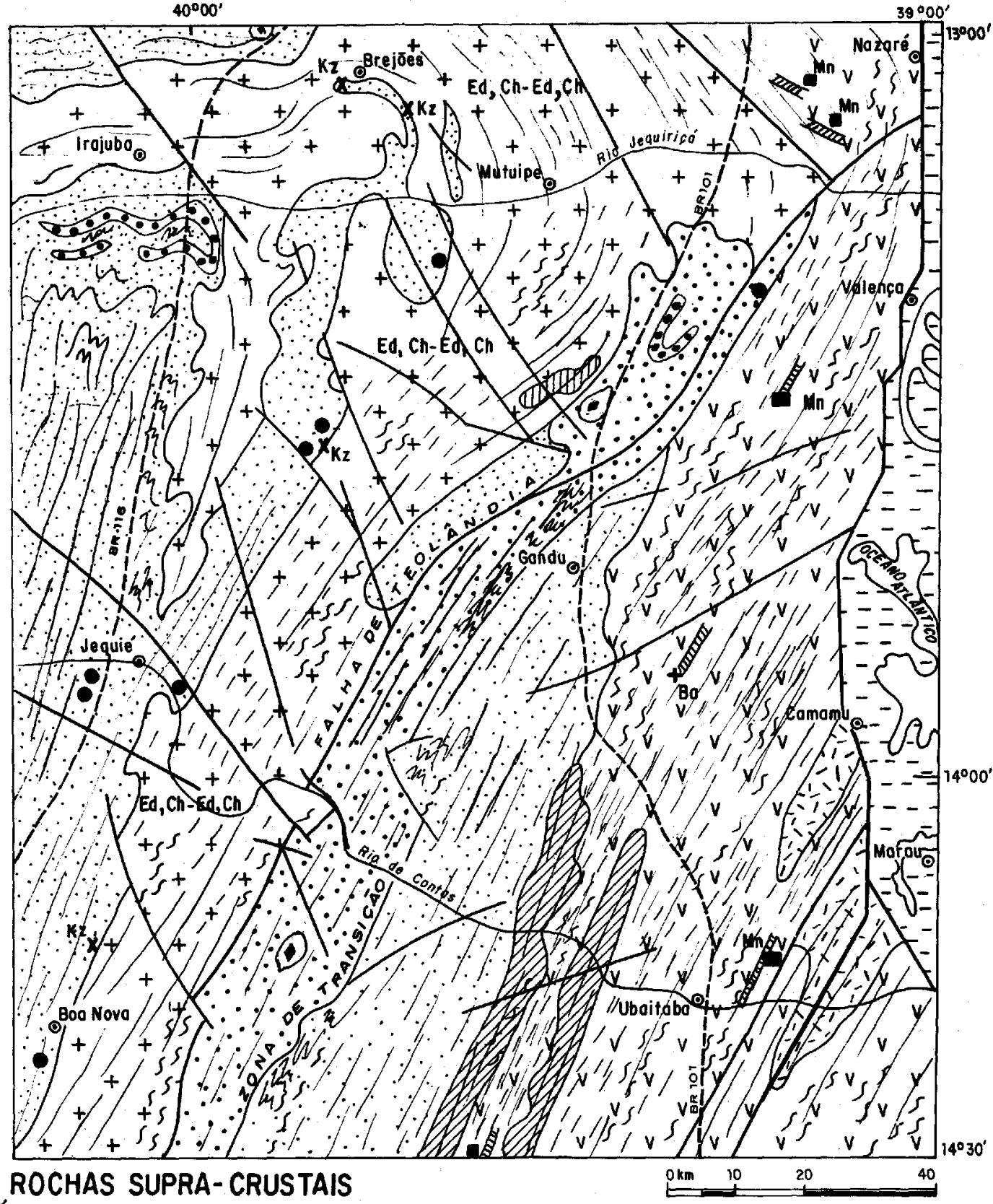

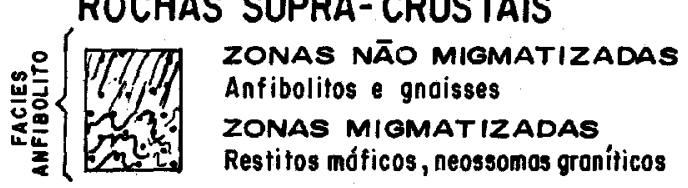

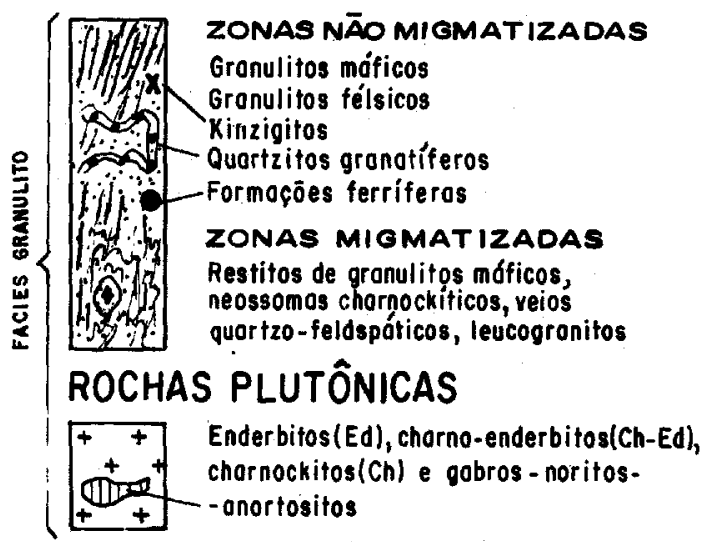

Figura 1 - Mapa geológico da região gramulítica do Sul da Bahia Figure 1 - Geologic map of the Southern Bahia granulitic region

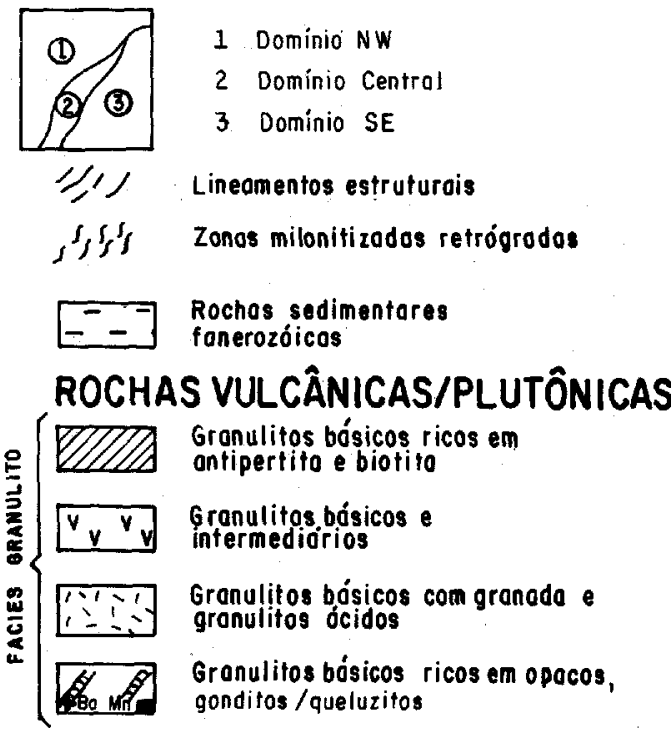


Tabela 1 - Composição mineralógica das rochas da região granulítica do Sul da Bahia

Table 1-Mineralogical composition of the Southem Bahia granulitic region rocks

\begin{tabular}{|c|c|c|c|}
\hline ROCHAS & $\begin{array}{l}\text { MINERAISMETAMÓRFICOS } \\
\text { PRINCIPAIS } \\
\text { (Composiçäo Modal) }\end{array}$ & $\begin{array}{l}\text { MINERAIS } \\
\text { ACESSORIOS }\end{array}$ & $\begin{array}{l}\text { MINERAIS } \\
\text { SECUNDÁRIOS }\end{array}$ \\
\hline \multicolumn{4}{|l|}{ DOMINIONW } \\
\hline Enderbitos & $\begin{array}{l}\text { Plagantp }(60 \%)(\mathrm{An} 30) ; \mathrm{Opx}(2-5 \%) ; \\
\text { Cpx (5-10\%); Hb(5-8);Qz(2-3\%);Bi; Hp }\end{array}$ & Op; Zr; Ap & Plag; Mu; Se;En; Mir \\
\hline Charno-Enderbitos & $\begin{array}{l}\text { Mp (30-40\%); Plag antp (30\%)(An 25); } \\
\text { Opx(5-10\%); Cpx (2-5\%); Hb (10\%); } \\
\text { Qz (5-10\%) }\end{array}$ & Op; Zr; Ap & $\begin{array}{l}\mathrm{Hb} ; \mathrm{Bi} ; \mathrm{Mic} ; \mathrm{Plag} ; \mathrm{Clr} ; \\
\mathrm{En} ; \mathrm{Mir} ; \mathrm{Se}\end{array}$ \\
\hline Charnockitos & $\begin{array}{l}\mathrm{Mp}(40-50 \%) ; \mathrm{Oz}(30 \%) ; \text { Plag antp (10\%) } \\
(\mathrm{An} 23) ; \mathrm{Opx}(10 \%) ; \mathrm{Cpx}(2 \%) ; \mathrm{Hb} ; \mathrm{Bi}\end{array}$ & Op; Zr; Ap & $\begin{array}{l}\text { Hb; Bi; Mic; Plag; Clr; } \\
\text { En; Mir }\end{array}$ \\
\hline $\begin{array}{l}\text { Gabros-Noritos- } \\
\text { Anortositos }\end{array}$ & $\begin{array}{l}\text { Plag }(70 \%)(\operatorname{An} 45-50) ; \operatorname{Cpx}(20 \%) \\
\text { Opx }(10 \%) ; \mathrm{Hb}(5-10 \%)\end{array}$ & Op; Ap & $\mathrm{Hb} ; \mathrm{Bi} ; \mathrm{Clr} ; \mathrm{En}$ \\
\hline Granulitos Máficos & $\begin{array}{l}\text { Plag (50\%); Opx-Cpx (30\%); Hb(15\%); } \\
\operatorname{Bi}(5 \%)\end{array}$ & Op;AP & $\mathrm{Bi}$ \\
\hline Granulitos Félsicos & $\begin{array}{l}\mathrm{Qz}(50 \%) ; \mathrm{Mp}(40 \%) ; \mathrm{Plag}(5-10 \%) \\
\mathrm{Qz}(50 \%) ; \mathrm{Plag} \text { antp (40\%); Opx (5-10\%) }\end{array}$ & $\begin{array}{l}\text { Op } \\
\text { Op }\end{array}$ & $\begin{array}{l}\mathrm{Se} \\
\mathrm{Se}\end{array}$ \\
\hline Kinzigitos & $\begin{array}{l}\text { Gt(35\%); Qz (30\%); Plag (15\%); } \\
\text { Cd(10\%); Bi (5\%); Sill }\end{array}$ & Op;Ap; Zr; Gf & \\
\hline Quartzito Granatífero & $\begin{array}{l}\text { Qz(70-90\%); Gt(5-10\%); Plag (1-5\%); } \\
\text { Opx; Bi }\end{array}$ & Op & $\mathrm{Bi} ; \mathrm{Clr}$ \\
\hline Formação Ferrifera & $\mathrm{Qz}(40-60 \%) ; \mathrm{Op}(60-40 \%)$ & & \\
\hline Restitos & $\begin{array}{l}\text { Plag (40-60\%);(An 30-35);Opx-Cpx } \\
(20-40 \%) ; \mathrm{Hb} ; \mathrm{Bi}\end{array}$ & $\mathrm{Op} ; \mathrm{Ap} ; \mathrm{Zr} ; \mathrm{Qz}$ & $\mathrm{Hb} ; \mathrm{Bi}$ \\
\hline Neossoma Charnockítico & $\begin{array}{l}\text { Mp (20-60\%); Plagantp (5-20\%) } \\
\text { An }(25-30) ; \text { Opx }(5-10 \%) ; Q z(5-20 \%) \\
\text { Cpx; Hb;Bi }\end{array}$ & Op;Zr; Ap; Gt & $\begin{array}{l}\mathrm{Hb} ; \mathrm{Bi} ; \mathrm{Mic} ; \mathrm{Plag} ; \mathrm{Clr} ; \\
\mathrm{En} ; \mathrm{Mir} ; \mathrm{Mu} ; \mathrm{Epi} \text { Tr }\end{array}$ \\
\hline Veios Quartzo-Feldspáticos & $\begin{array}{l}\text { Mp (50-60\%); Qz (20-30\%); Plag antp } \\
(5 \%)(\text { An 25-30);Opx-Cpx; Hb;Bi }\end{array}$ & $\mathrm{Op}, \mathrm{Zr}$ & $\begin{array}{l}\mathrm{Hb} ; \mathrm{Bi} ; \mathrm{Plag} ; \mathrm{Clr} ; \mathrm{Bt} ; \\
\text { Mir; Mic }\end{array}$ \\
\hline Leucogranitos & $\begin{array}{l}\text { Mp }(60-70 \%) ; \mathrm{Qz}(10-20 \%) ; \mathrm{Gt}(5 \%) ; \\
\text { Plag;Opx }\end{array}$ & Op; Zr & Se;Mir \\
\hline \multicolumn{4}{|l|}{ DOMINIOCENTRAL } \\
\hline Anfibolitos & $\begin{array}{l}\text { Plag(45\%)(An } 25-30) ; \mathrm{Hb}(40 \%) \\
\text { Cpx(5\%);Qz(1-5\%) }\end{array}$ & Op;Ap & $\mathrm{Se}$ \\
\hline Gnaisse Félsico & $\mathrm{Qz}(60 \%) ; \operatorname{Mic}(35 \%) ; \operatorname{Plag}(5 \%)$ & Op & $\mathrm{Se}$ \\
\hline \multicolumn{4}{|l|}{ DOMINIOSE } \\
\hline $\begin{array}{l}\text { Granulitos básicos ricos } \\
\text { em antipertita e biotita }\end{array}$ & $\begin{array}{l}\text { Plag antp (50\%); Opx (15\%); } \\
\text { Cpx (15\%);Bi }(15-20 \%)\end{array}$ & Op; Ap; Qz;Zr & Plag; Bi; Qz \\
\hline Granulitos Básicos & $\begin{array}{l}\text { Plag }(50 \%)(\text { An 55-60); Opx-Cpx (40\%); } \\
\text { Bi; Hb (5\%) }\end{array}$ & Op;Ap; Qz; Zr & $\mathrm{Hb} ; \mathrm{Bi} ; \mathrm{Qz}$ \\
\hline Granulitos Intermediários & Plag (70\%)(An 50); Opx-Cpx (20-25\%) & $\mathrm{Op} ; \mathrm{Qz} ; \mathrm{Ap} ; \mathrm{Zr}$ & $\mathrm{Bi} ; \mathrm{Qz}$ \\
\hline Granulito Básico com granada & $\begin{array}{l}\text { Plag (50\%); Opx (20\%); Cpx (20\%); } \\
\text { Gt(5\%) }\end{array}$ & $\begin{array}{l}\text { Op; } \mathrm{Ap} ; \mathrm{Zr} ; \mathrm{Qz} \\
\mathrm{Bi} ; \mathrm{Hb}\end{array}$ & \\
\hline Granulitos Ácidos & Plag antp (70\%); Opx (10-15\%); Qz (20\%) & Op;Mp & \\
\hline $\begin{array}{l}\text { Granulitos Básicos ricos } \\
\text { em opacos e granada }\end{array}$ & Plag (60\%); Opx-Cpx (15-20\%); Op(10\%) & $\mathrm{Hb} ; \mathrm{Bi}$ & $\mathrm{Gt}(10 \%)-\mathrm{Qz}$ \\
\hline
\end{tabular}

Abreviaturas: Opx. ortopiroxênio; Cpx. clinopiroxênio; Plag. antp. plagioclásio antipertítico; Mp. mesopertita; Hb. hornblenda; Bi. biotita; Qz quartzo; Gt. granada; Cd. cordierita; Sill. sillimanita; Mic. microclínio; Op. mineral opaco; Zr. zircão; Ap. apatita; Gf. grafita; Clr. clorita; Mu. muscovita; Se. sericita; En. enstatita alterada; Mir. mirmequita; Epi. Epídoto; Tr. tremolita; An. teor de anortita no plagioclásio

biotita rica em titânio, inclusas em plagioclásios, mas, também, por agregados de ortopiroxênio-clinopiroxênio com composição magmática típica (Bhattacharya 1971) e temperaturas de cristalização variando entre 900 e $1.000^{\circ} \mathrm{C}$ (Barbosa 1986, 1989,1990).
Corpos de gabros-noritos-anortositos, reequilibrados na fácies granulito também ocorrem na região, mas de forma muito restrita (Fig. 1). Sua mineralogia mais comum é mostrada na tabela 1. Eles têm características petrográficas e petroquímicas distintas das rochas anteriores (Barbosa 1986, Barbosa \& 
Fonteilles 1989, Cruz 1989). Evidências de campo tais como "margens resinadas" indicam que eles foram intrusivos nas rochas enderbíticas-charnockíticas (Cruz 1989).

\section{Rochas supracrustais metamorfizadas na fácies} granulito (Domínio NW) Ainda no domínio NW, aparentemente sobre as plutônicas anteriores, ocorrem rochas granulíticas com intercalações de bandas máficas e félsicas. As bandas máficas podem ter sido basaltos e/ou gabros, e as félsicas, podem ter tido como protólitos, ou tufos riolíticos-dacíticos, ou arcósios (Barbosa 1986) ou ainda charnoenderbitos-tonalitos (Barbosa 1991). Estas intercalações máficas-félsicas estão deformadas e recristalizadas na fácies granulito, verificando-se que, nem a petrografia nem a petroquímica permitem estabelecer se a natureza original e vulcânica ou plutônica (Barbosa 1991). Entretanto, no presente trabalho, estas intercalações estão sendo consideradas preferencialmente como lendo uma origem vulcânica, sobretudo porque: nas análises químicas de microssonda eletrônica (Barbosa 1986, 1989, 1990), realizadas nas bandas de granulitos máficos, só foram encontrados piroxênios equilibrados no pico do metamorfismo (tipomorfos), fato que não ocorre nos granulitos máficos da região, aqueles com evidências texturais claramente plutônicas, que mostram duas duplas de Opx-Cpx, uma tipomorfa e outra ígnea, esta última com temperaturas plutônicas, parcialmente reequilibradas pelo metamorfismo, estimadas em torno de $920^{\circ} \mathrm{C}$; e nas observações de campo, verifica-se íntima associação dessas bandas com kinzigitos, quartzitos granatíferos, formações ferríferas-manganesíferas e níveis grafitosos.

Essas rochas supracrustais apresentam-se na região em duas formas de ocorrência características: na primeira, apesar de se notar metassomatismo e remobilizações quartzo-feldspáticas restritas, elas exibem uma estrutura essencialmente gnáissica/ bandada (zonas não-migmatizadas); na segunda, essas supracrustais mostram-se com feições de migmatitos e até de anatexitos, quando não se verifica mais, com clareza, as estruturas gnáissicas/bandadas anteriores (zonas migmatizadas).

ZONAS NÃO-MIGMATIZADAS Essas zonas são caracterizadas essencialmente por bandas lateralmente contínuas de granulitos máficos e félsicos (Foto 1), de espessuras variáveis, mas dificilmente ultrapassando um metro, com contatos abruptos e incluindo intercalações de kinzigitos, quartzitos granatíferos e formações ferríferas bandadas (Fig. 1).

Os granulitos máficos, em geral de granulação média, são ricos em plagioclásio e piroxênio ocorrendo subordinadamente hornblenda e biotita (Tab. 1).

Os granulitos félsicos são também de granulação média, apresentando mineralogia ora composta de quartzo e feldspato pertítico e, ora de quartzo, plagioclásio antipertítico e raros ortopiroxênios. Com espessuras variando de poucos centímetros a poucos metros, uma feição marcante nessas bandas félsicas é o fato de possuírem composição mineralógica e química constante por longas distâncias (> $300 \mathrm{~m})$, não havendo evidências de expressivas remobilizações durante 0 metamorfismo.

Os kinzigitos são encontrados, em geral, próximos ao contato entre as rochas plutônicas enderbíticas-charnockíticas e entre as rochas supracrustais, em um padrão de distribuição que pode indicar que eles ocuparam a porção basal dessas supracrustais (Fig. 1). Eles formam bandas alternadas $(5 \mathrm{~cm}$ $2 \mathrm{~m}$ ), intercaladas com bandas de granulitos félsicos ricas em quartzo e feldspato potássico pertítico. São compostos de granada, quartzo, plagioclásio, cordierita, biotita e sillimanita, chamando a atenção para a presença de grafita como mineral acessório (Barbosa 1986,1990).

Quartzitos granatíferos também ocorrem subordinadamente nessas rochas supracrustais sendo representadas por camadas ( $1-10 \mathrm{~m}$ de espessura) de quartzo e almandina, ocorrendo em menor quantidade plagioclásio, ortopiroxênio e biotita, inclusos em restritos, estreitos e concordantes níveis de material máfico. Sua composição mineraló gica é mostrada na tabela 1 .

Formações ferríferas bandadas aparecem em afloramentos isolados e sob a forma de intercalações dentro de outras rochas granulíticas. Algumas vezes elas podem alcançar espessuras de um a cinco metros e comprimentos em torno de $500 \mathrm{~m}$. São formadas de quartzo $(40-60 \%)$ e opacos $(60$ $40 \%$ ) (Tab. 1).

ZONAS MIGMATIZADAS Em áreas restritas, onde a pressão de fluidos e a temperatura da fácies granulito foi adequada, há indícios que ocorreu fusão parcial in situ, acompanhada por remobilizações e metassomatismo potássico, misturando e destruindo parcialmente as bandas máficas e félsicas, dando origem às zonas migmatizadas na fácies granulito (Foto 2). Em afloramentos típicos desses migmatitos granulíticos, pode-se distinguir restitos de granulitos básicos biotitizados, neossomas charnockíticos, veios quartzo-feldspáticos e leucogranitos ricos em granada.

Os restitos/paleossomas ocorrem como blocos de cor preta, enclaves ou boundins de tamanho variável (centimétrico a métrico), inclusos dentro do neossoma chamockítico. A parte interna desses restitos tem assembléia mineral semelhante àquela das bandas de granulitos máficos das zonas não-migmatizadas descritas anteriormente, mas são mais ricos em hornblenda e biotita, especialmente nos seus bordos (Barbosa 1986,1990).

Os neossomas charnockíticos, pouco ou nada deformados, são heterogêneos em composição, dependendo do grau de anatexia e metassomatismo. Eles têm granulometria de média a grossa e são de cor verde-escura. Grandes cristais de mesopertita e microclínio pertítico, plagioclásio antipertítico, ortopiroxênio e quartzo são os minerais principais, ocorrendo em quantidades subordinadas, clinopiroxênio, hornblenda e biotita (Tab. 1).

Veios quartzo-feldspáticos ocorrem nos migmatitos granulíticos, cortando os neossomas charnockíticos e às vezes os restitos máficos. Eles são verde-claros, não-deformados e mineralogicamente homogêneos, compostos de mesopertita e microclínio pertítico, quartzo e plagioclásio antipertítico (Tab. 1).

Leucogranitos também ocorrem nas zonas migmatizadas, especialmente associados a rochas kinzigíticas, sugerindo origem anatética (granites do tipo S). Eles formam corpos irregulares de tamanho variável (métrico a hectométrico) e são muito pouco deformados. São constituídos essencialmente de mesopertita, quartzo e granada. Plagioclásio e ortopiroxênio ocorrem subordinadamente (Tab. 1).

Rochas supracrustais metamorfizadas na fácies an-
fibolito (Domínio Central) Semelhantemente ao que foi descrito para as rochas supracrustais metamorfizadas na fácies granulito, no Domínio Central, da fácies anfibolito, também ocorrem intercalações máficas e félsicas; é difícil estabelecer sua natureza original, podendo ser vulcânicas e/ou plutônicas, com protólitos similares àqueles interpretados para as intercalações máficas-félsicas do Domínio NW, anterior. Elas também possuem dois modos de ocorrência mais importantes, aqui novamente denominados de zonas não-migmatizadas e zonas migmatisadas.

ZONAS NÃO-MIGMATIZADAS Embora de ocorrência muito restrita, essas zonas estão representadas por bandas de anfibolitos $(030-4,0 \mathrm{~m})$ intercalados em bandas de gnaisses félsicos $(0,10-5,00 \mathrm{~m})$, quartzitos e formação ferrífera bandada. Os anfibolitos contêm plagioclásio e hornblenda azul esverdeada, ocorrendo subordinadamente clinopiroxênio, quartzo e opacos. Os gnaisses félsicos são foliados e compostos essencialmente de quartzo, microclínio e plagioclásio sericitizado (Tab 1). 
ZONAS MIGMATIZADAS Processos semelhantes àqueles que geraram os migmatitos granulíticos do Domínio NW, descritos anteriormente, parece que atuaram também no Domínio Central da região em estudo. Apesar de ocorrências restritas, os migmatitos dessas zonas exibem indicações de que estão na fácies anfibolito. São formados essencialmente de restitos máficos e neossomas graníticos.

Os restitos/paleossomas máficos dessas zonas migmatizadas do Domínio Central possuem morfologia e disposição espacial nos afloramentos, semelhante aos resistatos máficos dos migmatitos granulíticos. Entretanto, o ortopiroxênio é ausente, sua mineralogia é semelhante dos anfibolitos das zonas não-migmatizadas descritas acima.

Os neossomas por sua vez têm composição granítica e são constituídos essencialmente de quartzo, microclínio e plagioclásio, tendo hornblenda e biotita como minerais subordinados (Tab. 1). De forma semelhante aos neossomas charnockíticos, também englobam blocos e boundins de restitos máficos.

\section{ZONA DE TRANSIÇÃO GRANULITO-ANFIBOLITO}

O Domínio Central da região em foco é separado abruptamente das rochas enderbíticas-charnockíticas do Domínio NW pela Falha de Teolândia (Fig. 1) (Mascarenhas 1979). Contudo, o limite sudeste apresenta uma separação relativamente contínua pois, embora raramente, observa-se nessa zona de transição a transformação de bandas e/ou restitos anfibolíticos (Domínio Central) em bandas de granulitos máficos (Domínio SE). Amostras de litologias máficas coletadas nessa zona de transição mostram cristais de hornblenda marrom-esverdeados, rodeados por cristais de piroxênio. Estas texturas refletem reações metamórficas de desidratação, indicando que as rochas anfibolíticas do Domínio Central, na sua maioria, muito provavelmente foram formadas durante o metamorfismo progressivo.

Rochas vulcânicas e/ou plutônicas metamorfizadas na fácies granulitos (Domínio SE) No Domínio $\mathrm{SE}$ da região ocorrem rochas granulíticas cinza-escuras-esverdeadas, relativamente homogêneas. Elas foram fortemente deformadas no estado dúctil e completamente recristalizadas, o que torna difícil identificar sua natureza original, se vulcânica ou plutônica (Barbosa 1991). Dados de campo, petrográficos e geoquímicos, permitiram distinguir os quatro principais tipos litológicos descritos a seguir.

GRANULITOS BÁSICOS COM ANTIPERTITA E BIOTITA Esses granulitos têm granulação média a grossa e uma coloração cinza-escura, sendo caracterizados mineralogicamente pela presença de plagioclásio antipertítico e biotita, ambos em equilíbrio com os clino e ortopiroxênios, que são também relativamente abundantes na rocha (Barbosa 1986). Cristais menores de plagioclásio não-pertítico, preenchendo os interstícios dos minerais principais, estão também presentes na rocha, constituindo evidência do metamorfismo retrógrado a que a mesma foi submetida (Tab. 1).

\section{GRANULITOS BÁSICOS E INTERMEDIÁRIOS}

Essas rochas ocupam a maior porção da parte SE da região. Estão fortemente foliadas, verticalizadas e orientadas na direção N10 $10^{\circ}$ (Fig. 1). São constituídas por bandas alternadas de material básico, cinza-escuro (rico em piroxênios), e com material intermediário, cinza-claro (rico em plagioclásios). Como mostra a tabela 1, elas são compostas essencialmente de clinopiroxênio, ortopiroxênio e plagioclásio, sendo que os membros mais básicos são mais ricos nos dois primeiros minerais e os mais intermediários mais ricos no último (Tab. 1).

GRANULITOS BÁSICOS COM GRANADA E GRANULITOS ÁCIDOS Essas rochas são raras e situadas mais perto do Oceano Atlântico (Fig. 1). Os granulitos básicos com granada são compostos de plagioclásio, piroxênios e granada, esta última em fase de destruição, por causa de sua reação com o clinopiroxênio, produzindo uma paragênese composta de plagiocisio e ortopiroxênio. Esta reação metamórfica será discutida mais adiante. Os granulitos ácidos são caracterizados por plagioclásio antipertítico e grãos de quartzo estirados que definem a foliação da rocha.

\section{GRANULITOS BÁSICOS RICOS EM OPACOS}

Essas rochas são de ocorrência restrita e estão associadas a quartzitos granatíferos e metassedimentos granulitizados ricos em manganês do tipo gondito/queluzito (Toniatti \& Barbosa 1973, Valarelli et al 1982, Barbosa 1986). São compostos de uma assembléia onde predomina plagioclásio, piroxênio, opacos e granadas (Tab. 1), estas últimas formadas em fase retrógrada do metamorfismo pela reação Opx + Plag r Gt + Qz (Barbosa \& Fonteilles 1986, Barbosa 1986, 1988, 1989, 1990), discutida mais adiante.

METAMORFISMO Equilíbrio entre fases minerais Análises químicas de minerais, feitas em microssonda eletrônica, e resoluções termodinâmicas permitiram definir, nas rochas da região, duplas ou grupos de fases minerais em equilíbrio para utilização dos geotermômetros e geobarômetros. Para assegurar que duas fases minerais estão em equilíbrio, foram consideradas as condições de temperatura e pressão como fixas, e que as variações dos teores de elementos químicos presentes nas duas fases minerais associadas foram feitos proporcionalmente. Isto significa que em diagramas nos quais figuram constituintes químicos dessas fases minerais, que podem se trocar, as retas que são traçadas com base nessas composições não devem se cruzar. Nesse caso, diz-se que as fases minerais em estudo estão em equilíbrio. Isto pode ser traduzido por uma reta sobre um diagrama do tipo:

\section{$\log \frac{\mathrm{X} 1}{1-\mathrm{X} 1} \div \log \frac{\mathrm{X} 2}{1-\mathrm{X} 2}$}

onde XI e X2 representam frações molares dos constituintes que se trocam entre as duas fases consideradas.

EQUILÍBRIO ENTRE ORTOPIROXÊNIOS E CLINOPIROXÊNIOS Na figura 2, utilizou-se o elemento Mg que é trocado entre o ortopiroxênio e clinopiroxênio durante as variações dos parâmetros físicos do metamorfismo. Esta troca pode ser representada pela reação:

$\mathrm{CaMgSi}_{2} \mathrm{O}_{6}+\mathrm{FeSiO}_{2}=\mathrm{CaFeSi}_{2} \mathrm{O}_{6}+\mathrm{MgSiO}_{2}$

que na condiçð̃es de equilíbrio pode ser escrita por:

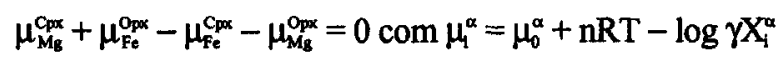

Nas relações acima jo. = potencial químico do componente $i$, na fase $\mathrm{a}, \mathrm{u}, \mathrm{n}=$ potencial químico de i puro, $\mathrm{R}=$ constante dos gases perfeitos, $\mathrm{T}=$ temperatura do sistema em ${ }^{\circ} \mathrm{K}, \mathrm{y} \sim$ coeficiente de atividade e $X=$ fração molar de i na fase a.

Admitindo-se que os coeficientes de atividades são aproximadamente constantes, isto é, a T constante e $\mathrm{X}$ de variações limitadas, obtém-se uma equação do tipo:

$\left(\frac{\mathrm{X}_{\mathrm{Mg}}^{\mathrm{Opx}}}{1-\mathrm{X}_{\mathrm{Mg}}^{\mathrm{O}_{\mathrm{px}}}}\right)+\left(\frac{\mathrm{X}_{\mathrm{Mg}}^{\mathrm{cpx}}}{1-\mathrm{X}_{\mathrm{Mg}}^{\mathrm{Cpx}}}\right)=\mathrm{Ctc}$

Considerando-se (i) o número de sítios ocupados pelos constituintes que se trocam nos dois minerais, (ii) a existência eventual de varios sítios não equivalentes, (iii) a saturação de certos sítios e, finalmente, (iv) a substituição de íons de tama- 
nhos diferentes, pode-se escrever a equação acima de uma forma mais generalizada, ou seja:

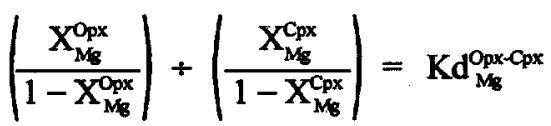

Sendo assim, é possível elaborar um diagrama utilizando nas coordenadas logarítmicas

$\frac{X_{M g}^{O p x}}{1-X_{M g}^{O_{p x}}}$ em função de $\frac{X_{M g}^{C p x}}{1-X_{M_{g}}^{C p x}}$

Se nesse diagrama os pontos representativos das análises químicas das duplas de piroxênios se situarem sobre uma mesma reta, pode-se dizer que estas duplas estão em equilíbrio nas mesmas condições físicas. O Kd (Coeficiente.de Partição) associado a esta reta, para n e n' fixos, depende da temperatura e eventualmente da pressão.

A figura 2 mostra que os pontos representativos dos teores em magnésio dos piroxênios de diversas rochas da região situam-se sobre retas aproximadamente paralelas, as quais são próximas da reta teórica $n=n '=1$. Salienta-se nessa figura que os piroxênios, considerados relíquias plutônicas das rochas enderbíticas-charnockíticas (Domínio NW), e dos granulitos básicos plutônicos (Domínio SE), com temperaturas de cristalização próximas de $1.000^{\circ} \mathrm{C}$ situam-se aproximadamente sobre uma reta de $\mathrm{Kd} \mathrm{Opx}-\mathrm{Cpx}=0,63$; os piroxênios tipomorfos da grande maioria das rochas da regiã 0 , com temperaturas de cristalização vizinhas de $800^{\circ} \mathrm{C}$, situam-se sobre uma reta de $\mathrm{Kd} O \mathrm{px}-\mathrm{Cpx}=0,63$; e, finalmente, os piroxênios fortemente afetados pelo metamorfismo retró grado possuem $\mathrm{Kd}$ mais baixos, em torno de 0,50. Constata-se, assim, que os coeficientes de partição da reação de troca do elemento $\mathrm{Mg}$ entre os ortopiroxênios da região aumentam com a temperatura. Este fato foi também demonstrado em outras regiões granulíticas do mundo (Binns 1962,Kretz 1961,1963, Davidson 1968,Manna \& Sen 1974, Bello et al. 1988).

O alinhamento dos pontos representativos das análises químicas das duplas de Opx-Cpx, tipomorfas (pico do metamorfismo) de diversas rochas da região, evidencia a uniformidade das condições físicas do metamorfismo granulítico. Isto, em conseqüência, sugere que o metamorfismo progressivo foi suficientemente forte para reequilibrar, na fácies granulito, todas as paragêneses anteriores de mais baixo grau, existentes nas litologias da área.

EQUILÍBRIO ENTRE ORTOPIROXÊNIOS E GRANADAS As granadas, não muito abundantes na região, têm sido encontradas somente em rochas da fácies granulito e em materiais de composição química favorável. De uma maneira geral, essas fases minerais ocorrem nas seguintes formas: (i) granadas reacionais, em fase de destruição devido a reação metamórfica $\mathrm{Gt}+\mathrm{CPx}+(\mathrm{Qz}) \mathrm{Opx}+$ Plag (Foto 3), presente em amostras dos denominados granulitos básicos com granada (Domínio SE); (ii) granadas idiomórficas/subidiomórficas, encontradas em alguns granulitos bá sicos, sobretudo em kinzigitos e quartzitos granatíferos (Domínio NW); e (iü) granadas em coroas ao redor de ortopiroxênios e opacos provenientes da reação anterior, no sentido da direita para a esquerda (Foto 4), que ocorrem nos granulitos básicos ricos em opacos e granada (Domínio SE).

As granadas são de fundamental importância para estimar a pressã o do metamorfismo, mas é necessário, antes, estabelecer 0 equilíbrio entre elas e os ortopiroxênios presentes na mesma rocha. Para isso, foi construído o diagrama de variação da concentração do magnésio entre estas fases minerais (Fig. 3), utilizado também em outras regiões granulíticas do mundo (Davidson 1968, Loomis 1977), e inclusive no norte da Bahia (Bello et al 1988), que considera o coeficiente de partição do $\mathrm{Mg}$

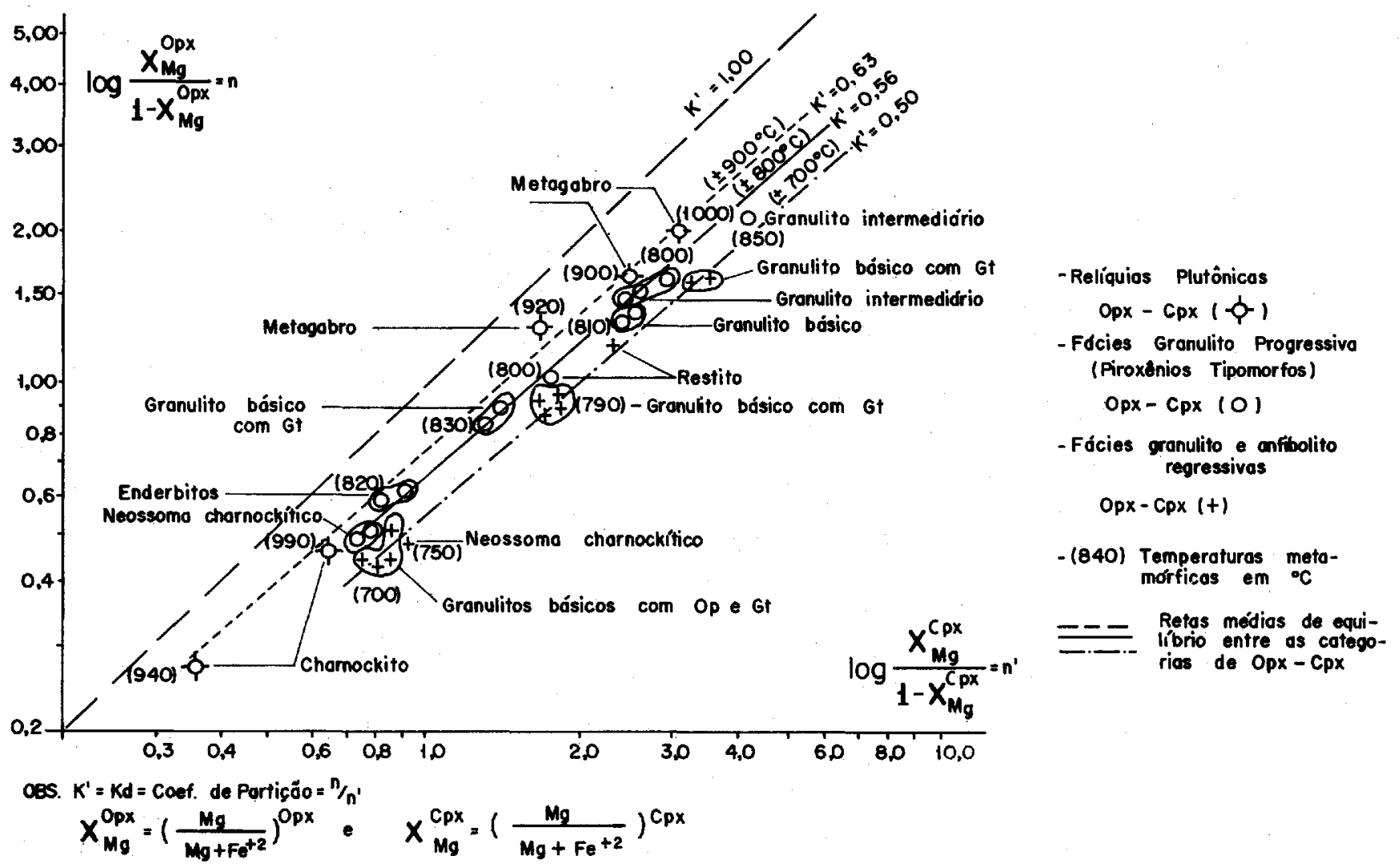

Figura 2 - Equilíbrio entre clinopiroxênios e ortopiroxênios Figure 2 - Chemical equilibria between clinopyroxenes and orthopyroxenes 

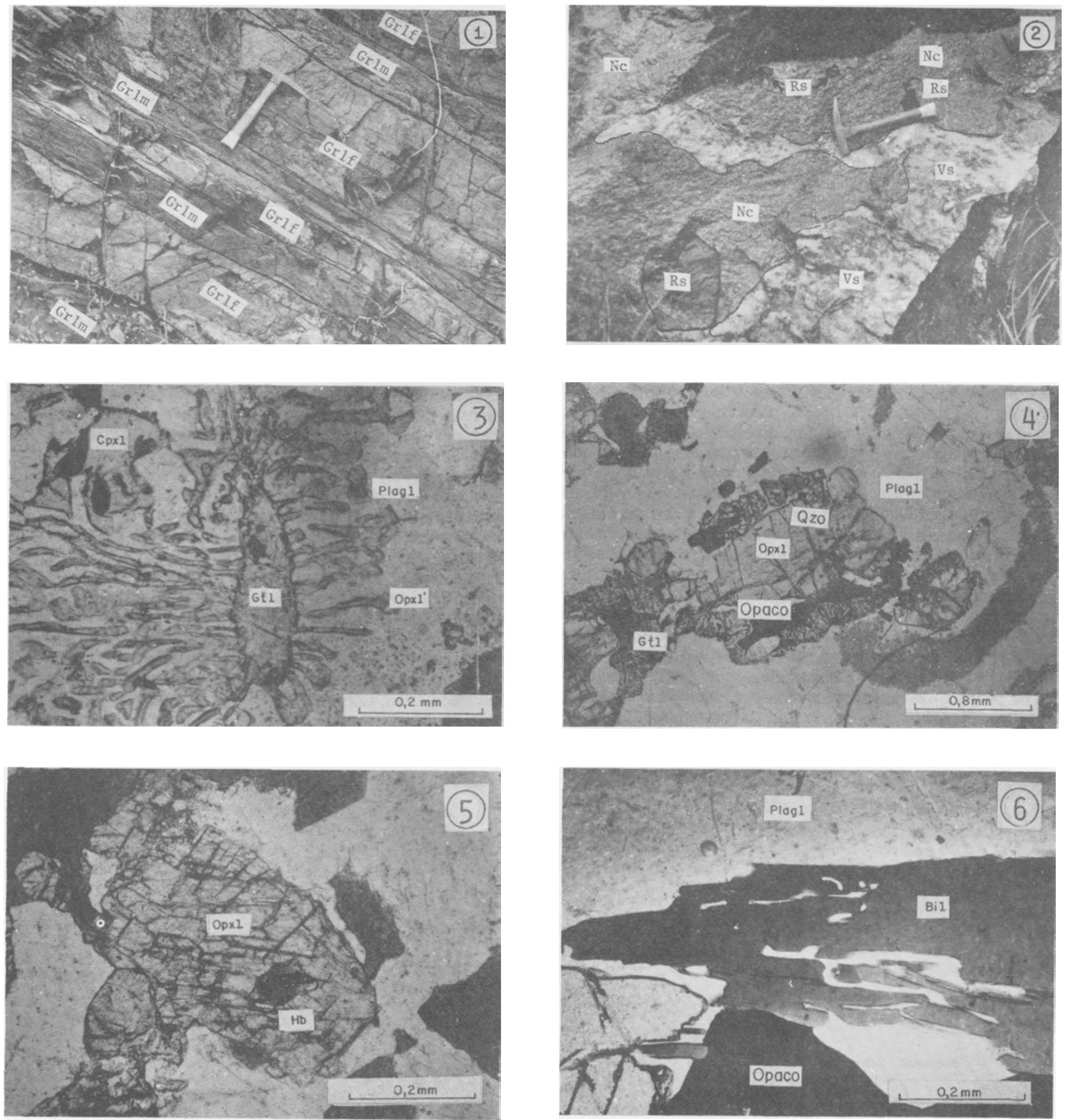

Prancha 1-Foto 1 Intercalates degranulitos máficos (Grlm) efélsicos (Grlf) das zonas não-migmatizadas (Domínio NW); Foto 2. Rochas heterogêneas das zonas migmatizadas denominadas de migmatitos granulíticos. Rs - resistatos de granulitos máficos; $\mathrm{Ne}$ - neossoma charnockítico; Vs - veios quartzo-feldspticos (Domínio NW); Foto 3. Reação metamórfica de destruição de granada $(G t+C p x Q z=O p x+$ Plag) (granulito básico com granada - Domínio SE); Foto 4. Reações metamórficos deformação de granada $(O p x+P l a g=G t+Q z e O p a c o+P l a g=G t+Q z)$ (granulito básico, rico em opacos - Domínio SE); Foto 5. Desenvolvimento de ortopiroxênio (Opx) a partir da hornblenda (Hb), segundo a reação de desidratação $H b+Q z=C p x+O p x$ + Plag $+\mathrm{H}_{2} \mathrm{O}$ (granulitos máficos - Zona de transição fades anfibolito - granulito); Foto 6. Biotita (Bi) em associação simpletítica comquartzo $(Q z)$, ao redor de opaco, produzida pela reação retrógrada (Opaco + Mesopertita $\left.+\mathrm{H}_{2} \mathrm{O}=\mathrm{Bi}+\mathrm{Qz}\right)($ Enderbitos Domínio. $N W$.

Obs.: As abreviaturas são as mesmas da tabela 1

Plate 1 - Photo 1. Intercalations of mafic (Grim) and felsic (Grlf) granulites of the non-migmatized zones (NW Domain); Photo 2. Heterogeneous rocks of the migmatized zones named granulitic migmatites. Nc - charnockitic neossoma, Vs - quartz-feldspar veins (NW Domain); Photo 3. Metamorphic reaction of garnet destruction (Gt $+\mathrm{Cpx}+\mathrm{Qz}-\mathrm{Opx}+\mathrm{Plag})$ (basic granulites with garnet - SE Domain); Photo 4. Metamorphic reaction of garnet formation (Opx + Plag I Gt + Qz e Opac + Plag - Gt + Qz) (opac rich basic granulites - SE Domain); Photo 5. Orthopyroxene development (Opx) from hornblende (Hb), following the dehydration reaction $\mathrm{Hb}+\mathrm{Qz}=\mathrm{Opx}+\mathrm{Cpx}+\mathrm{Plag}+\mathrm{H}_{2} \mathrm{O}$ (mafic granulites - granulite-amphibolite fades transition zone); Photo 6. Simplectitic association of quartz $(\mathrm{Qz})$ and biotite $(\mathrm{Bi})$, around opac, resulting from the retrograding reaction (Opac + Mesopertite $\left.+\mathrm{H}_{2} \mathrm{O}=\mathrm{Bi}+\mathrm{Qz}\right)$ (Enderbites - NW Domain. Obs.: Abreviations are the same as those on table 1 


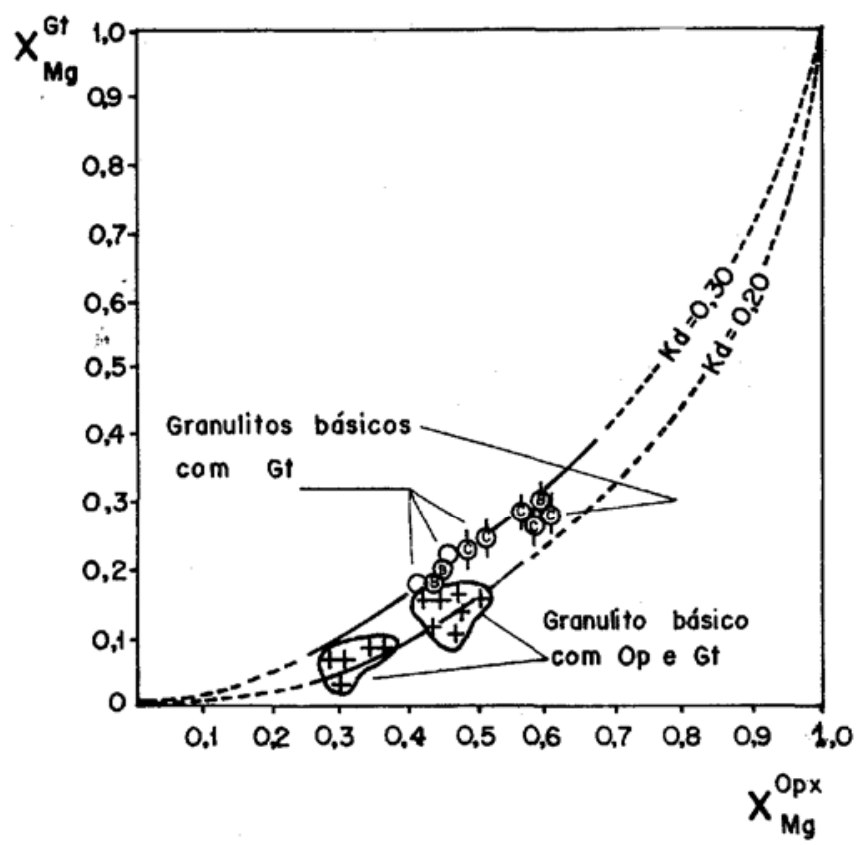

- Fácies Granulito Progressiva (minerais tipomorfos)

\section{() 1 Gronodas reacionais (centro e bordas) \\ O Granadas isomórficas / sub-isomórficas}

- Fácies Granulito e Anfibolito Regressivas

+ Granadas em côroas

$$
K_{d g}^{G t-O p x}=\frac{X_{M g}^{G t}\left(1-X_{M g}^{O p x}\right)}{X_{M g}^{O p x}\left(1-X_{M g}^{G \dagger}\right)}
$$

OBS.: Não foram incluidas as granadas dos quartzítos, granatíferos e dos kinzigitos.

\section{Fïgura 3-Equilibrio entre ortopiroxênios e granada}

Figure 3-Chemical equilibria between orthopyroxenes and garnet

na granada como um indicador das condições de equilíbrio de cristalizacão desse mineral. Nele se observa que as granadas reacionais (Foto 3) e as isomórficas/subisomórficas possuem um mesmo coeficiente de partição $(\mathrm{Kd})$, para o elemento $\mathrm{Mg}$, de aproximadamente 030, tanto nas bordas como nos centros. Este resultado leva interpretação de que essas fases minerais foram equilibradas com os ortopiroxênios, na temperatura do metamorfismo granulítico. Com relação às granadas em coroas ao redor de ortopiroxênios e opacos (Foto 4), verifica-se que possuem valores de $\mathrm{Kd}$, para o $\mathrm{Mg}$, mais baixos, da ordem de 0,20 e com os pontos representativos de suas análises químicas mais dispersos que as anteriores, podendo ser interpretadas como tendo sido formadas em condições retrógradas. Efetivamente, as rochas que incluem essas granadas em coroas apresentam temperaturas meíamórficas mais baixas que as rochas dos dois tipos precedentes.

Principais reações metamórficas $\mathrm{Na}$ região granulítica do sul da Bahia foram identificadas diferentes reações metamórficas que se mostraram importantes na caracterização dos estágios de temperatura e pressão que ocorreram durante o metamorfismo. As mais importantes, estudadas com base na petrografia e na microssonda eletrônica, são descritas a seguir.
REAÇÕES DE DESIDRATAÇÃO-HIDRATAÇÃO Nos níveis de granulitos máficos, situados na zona de transição fácies anfibolito-granulito (Fig. 1), identificam-se grãos subarredondados de hornblenda de cor verde-amarronzada, rodeados por ortopiroxênios (Foto 5) e/ou clinopiroxênios. Nessa zona, constata-se que a quantidade de hornblenda é cada vez menor a medida que se desloca para o Domínio SE, claramente da fácies granulito. Esta transformação progressiva pode ser representada pela reação de desidratação $\mathrm{Hb}+$ $\mathrm{Qz}=\mathrm{Opx}+\mathrm{Cpx}+\mathrm{Plag}+\mathrm{H}_{2} \mathrm{O}$, que é contínua (Sen \& Ray 1971, Winkler 1977), já que todas essas fases minerais coexistem em equilíbrio, dentro de um certo intervalo de temperatura e pressão de água.

Nessa zona de transição, há em certos granulitos a presença de biotitas em inclusões nos ortopiroxênios. A transformação da biotita em ortopiroxênio se faz segundo a reação contínua $\mathrm{Bi}+\mathrm{Qz}=\mathrm{Opx}+$ Mesopertita $+\mathrm{H}_{2} \mathrm{O}$, que também é considerada como característica da passagem da fácies anfibolito fácies granulito (Winkler 1977). Admite-se que essas duas reações de desidratação produzem-se em resposta à elevação da temperatura do metamorfismo progressivo. Apesar disso, na maioria das rochas da região, sobretudo nos granulitos máficos, observam-se associações minerais com características que já podem ser explicadas pelo funcionamento das duas reações anteriores, mas, no sentido inverso, da direita para a esquerda. Assim, simplectitos de hornblenda mais quartzo ou biotita mais quartzo ao redor de piroxênios e opacos (Foto 6) são manifestações do metamorfismo retrógrado. Esses simplectitos podem ocorrer sem orientação (metamorfismo retrógrado estático) ou deformados e orientados nos planos de bandamento/foliação da rocha (metamorfismo retrógrado dinâmico), associados a deformações tardias posteriores ao pico metamórfico.

REAÇÃO DE DESESTABILIZAÇÃO PARCIAL DAS GRANADAS Nos denominados "granulitos básicos com granada", situados no Domínio SE da região (Fig. 1), apresentam, ao microscópio, cristais de granada em vias de transformação em ortopiroxênio e plagioclásio (Foto 3). Essa transformação está ligada à reação metamórfica $\mathrm{Gt}+\mathrm{Cpx}+$ $(\mathrm{Qz})=\mathrm{Opx}+$ Plag.

Esta reação, também encontrada em outros terrenos granulíticos do mundo (Irving 1974, Wagner \& Crawford 1975, Coolen 1980, Convert 1981), foi intensamente estudada por Green \& Ringwood (1976), que a definiu como muito sensível às modificações da pressão do metamorfismo. O primeiro membro dessa reação pode representar uma assembléia metamórfica de mais alta pressão em relação aquele do segundo membro. Há casos nessas rochas em que a desestabilização da granada prossegue até o desaparecimento quase total desse mineral substituído por ortopiroxênio e plagioclásio, os quais reconhecidamente constituem uma assembléia de mais baixa pressão no metamorfismo granulítico (Green \& Ringwood 1967, Coolen 1980, Convert 1981).

REAÇÃO DE FORMAÇÃO DE COROAS DE GRANADAS Nos granulitos básicos, ricos em opacos e granada, são verificadas reações de desestabilização dos ortopiroxênios e dos opacos, que são materializadas pela formação de coroas simplectíticas de granada e quartzo (Foto 4). Estas se desenvolvem segundo as reaçõ es: Opx + Plag - Gt $+\mathrm{Qz}+(\mathrm{Cpx})$ e Ilmenita + Plag - Gt + Qz. O plagioclásio que participa dessa reação contém $35 \%$ de anortita e a granada produzida contém 20\% de grossulária (Barbosa 1986). Wagner \& Crawford (1975), Manna \& Sen (1974) e Ellis \& Green (1985) foram alguns dos autores que estudaram essas reações. Eles chegaram à conclusão de que elas podem ocorrer por aumento de pressão mas são produzidas sobretudo por causa da queda da temperatura do metamorfismo. Efetivamente, nessas rochas foram registradas as mais baixas 
temperaturas metamórfícas da região, em torno de $700^{\circ} \mathrm{C}$ (Tab. 3), consideradas retrógradas, próximas do limite entre as fácies granulito e anfíbolito.

\section{ASSOCIAÇÕES - PARAGÊNESES MINERAIS}

A tabela 2 exibe as principais associações minerais das rochas metamórfícas da regio nas diferentes fácies metamórfícas, podendo-se concluir que: (i) no domínio da fácies anfíbolito progressivo (Domínio Central), entre as rochas ácidas, predomina a paragênese quartzo+microclínio+plagioclásio e, entre as rochas básicas, plagioclásip+hornblenda+clinopiroxênio; (ii) no domínio da fácies granulito (Domínios NW e SE), entre as rochas ácidas são verificadas paragêneses compostas de mesopertíta e/ou plagioclásio antipertítico+quartzo+ortopiroxênio e, entre as rochas básicas e intermediárias, plagioclásio antipertítico-i-ortopiroxênio+clinopiroxênio; (iii) a hornblenda e biotita em equilíbrio com o ortopiroxênio ocorrem em quantidades subordinadas e as granadas aparecem somente em rochas granulítícas de composição química particular; e (iv) as paragêneses metamórfícas secundárias formadas pelo retrometamorfismo, nas condições das fácies anfibolito e xisto-verde, são constituídas essencialmente de hornblenda+biotita+plagioclásio+microclínio e biotita+clorita+enstatita alterada+quartzo, respectivamente.

Tabela 2 - Paragêneses minerais das rochas da região granulitica do Sul da Bahia

Table 2 - Mineral paragenesis of the Southern Bahia granulitic region rocks

\begin{tabular}{|c|c|c|c|c|}
\hline ROCHAS & $\begin{array}{c}\text { FÁCIES } \\
\text { ANFIBOLITO } \\
\text { PROGRESSIVO }\end{array}$ & FÁCIES GRANULITO & $\begin{array}{c}\text { FÁCIES } \\
\text { ANFIBOLITO } \\
\text { REGRESSIVO }\end{array}$ & $\begin{array}{l}\text { FÁCIES } \\
\text { XISTO VERDE } \\
\text { REGRESSIVO }\end{array}$ \\
\hline \multicolumn{5}{|l|}{ DOMÍNIONW } \\
\hline Enderbitos & & Plag antp-Opx-Cpx-Mp-(Qz-Hp) & (Hb-Bi-Plag) & (En-Mu-Se) \\
\hline Charno-Enderbitos & & Plag antp-Mp-Opx-Qz(Hb-Cpx) & (Hb-Bi-Mic-Plag & (En-Clr-Se) \\
\hline Charnockitos & & $\begin{array}{l}\text { Mp-Qz-Plag antp-Opx-Hb- } \\
\text { (Cpx-Bi) }\end{array}$ & (Hb-Bi-Mic-Plag & (En-Clr) \\
\hline $\begin{array}{l}\text { Gabro-Noritos } \\
\text { Anortositos } \\
\end{array}$ & & Plag-Opx-Cpx(Hb-Bi) & (Hb-Bi) & (En-Clr) \\
\hline Granulitos Máficos & & Plag-Opx-Cpx-Hb(Bi) & $(\mathrm{Hb}-\mathrm{Bi})$ & \\
\hline Granulitos Félsicos & & $\begin{array}{l}\text { Qz-Mp(Plag) } \\
\text { Qz-Plag antp(Opx) }\end{array}$ & & Se-En \\
\hline Kinzigitos & & Gt-Qz-Plag-Cd(Bi-Sill) & & \\
\hline $\begin{array}{l}\text { Quartzito } \\
\text { Granatífero }\end{array}$ & & Qz-Gt-(Plag-Opx-Bi) & & En-Clr \\
\hline Formação Ferrífera & & Qz-Op & & \\
\hline Restito & & Plag-Opx-Cpx-Hb(Bi) & (Hb-Bi-Qz) & \\
\hline $\begin{array}{l}\text { Neossoma } \\
\text { Charnockítico }\end{array}$ & & $\begin{array}{l}\text { Mp-Plag antp-Opx-Qz } \\
\text { (Cpx-Hb-Bi) }\end{array}$ & (Hb-Bi-Mic-Plag & (En-Clr-Mu-Epi) \\
\hline $\begin{array}{l}\text { Veios quartzo- } \\
\text { feldspáticos }\end{array}$ & & $\begin{array}{l}\text { Mp-Qz-Plag antp- } \\
\text { (Opx-Cpx-Hb-Bi) }\end{array}$ & (Hb-Bi-Mic-Plag & (En-Clr) \\
\hline Leucogranitos & & Mp-Qz-Gt(Plag-Opx) & & $\mathrm{Se}$ \\
\hline \multicolumn{5}{|l|}{ DOMINIOCENTRAL } \\
\hline Anfibolitos & Plag-Hb-Qz & Plag-Hb(Cpx-Qz) & & $\mathrm{Se}$ \\
\hline Gnaisse Félsico & Hb-Qz-(Plag) & Qz-Mic-(Plag) & & $\mathrm{Se}$ \\
\hline \multicolumn{5}{|l|}{ DOMÍNIOSE } \\
\hline $\begin{array}{l}\text { Granulitos Básicos com } \\
\text { antipertita e biotita }\end{array}$ & & Plag antp-Opz-Cpx (Bi) & $(\mathrm{Qz}-\mathrm{Bi})$ & En \\
\hline Granulitos Básicos & & Plag antp-Opx-Cpx (Bi-Hb) & $(\mathrm{Hb}-\mathrm{Bi}-\mathrm{Qz})$ & \\
\hline $\begin{array}{l}\text { Granulitos Interme- } \\
\text { diários }\end{array}$ & & Plag-Opx-Cpx & $(\mathrm{Bi}-\mathrm{Qz})$ & \\
\hline $\begin{array}{l}\text { Granulitos Básicos } \\
\text { com granada }\end{array}$ & & Plag-Opx-Cpx-Gt & $(\mathrm{Bi}-\mathrm{Qz})$ & \\
\hline Granulitos Ácidos & & Plag antp-Opx-Qz & & \\
\hline $\begin{array}{l}\text { Granulitos Básicos com } \\
\text { opacos e granada }\end{array}$ & & Plag-Opx-Cpx-Op & $\begin{array}{l}\text { Gt-Qz } \\
(\mathrm{Hb}-\mathrm{Bi})\end{array}$ & (En) \\
\hline
\end{tabular}

Obs.: As abreviaturas utilizadas são as mesmas da tabela 1 
Tabela 3 - Temperaturas $\left({ }^{\circ} \mathrm{C}\right)$ metamórficas de rochas da região granulitica do Sul da Bahia

Table 3 - Metamorphic temperatures $\left({ }^{\circ} \mathrm{C}\right)$ of the Southern bahia granulitic region rocks

\begin{tabular}{|c|c|c|c|c|c|c|}
\hline ROCHAS & $\begin{array}{c}\text { TIPOS DE } \\
\text { DUPLASDE } \\
\text { PIROXENIOS } \\
\end{array}$ & $\begin{array}{c}\text { WOOD \& } \\
\text { BANNO } \\
(1973) \\
\end{array}$ & $\begin{array}{l}\text { WELLS } \\
\text { (1977) }\end{array}$ & $\begin{array}{c}\text { ELLIS \& } \\
\text { GREEN } \\
\text { (1979) }\end{array}$ & $\begin{array}{c}\text { GANGUL } \\
\text { (1979) }\end{array}$ & $\underset{\text { (1988) }}{\text { KROGH }}$ \\
\hline \multicolumn{7}{|l|}{ DOMÍNIONW } \\
\hline Enderbito & Tipomorfa & 818 & 881 & & & \\
\hline Enderbito & Tipomorfa & 807 & 865 & & & \\
\hline Charnockito & Relíquia & 884 & 988 & & & \\
\hline Charnockito & Relíquia & 891 & 988 & & & \\
\hline Gabro-Norito-Anortositos & Tipomorfa & 824 & 888 & & & \\
\hline Gabro-Norito-Anortositos & Lamelas & 794 & 844 & & & \\
\hline Gabro-Norito-Anortositos & Relíquia & 900 & 951 & & & \\
\hline Gabro-Norito-Anortositos & Relíquia & 911 & 981 & & & \\
\hline Granulitos Máficos & Tipomorfa & 847 & 901 & & & \\
\hline Restito & Lamelas & 794 & 829 & & & \\
\hline Restito & Lamelas & 811 & 838 & & & \\
\hline Neossoma Charnockítico & Lamelas & 788 & 836 & & & \\
\hline Neossoma Charnockítico & Tipomorfa & 817 & 881 & & & \\
\hline \multicolumn{7}{|l|}{ DOMÍNIOSE } \\
\hline Granulito Intermediário & Tipomorfa & 837 & 848 & & & \\
\hline Granulito Intermediário & Lamelas & 811 & 824 & & & \\
\hline Granulito Intermediário & Tipomorfa & 828 & 848 & & & \\
\hline Granulito Intermediário & Tipomorfa & 856 & 856 & & & \\
\hline Granulito Intermediário & Lamelas & 742 & 730 & & & \\
\hline Granulito Intermediário & Lamelas & 804 & 826 & & & \\
\hline Granulito Básico com granada & Lamelas & 807 & 854 & 810 & 824 & 790 \\
\hline Granulito Básico com granada & Tipomorfa & 827 & 884 & 820 & 870 & 795 \\
\hline Granulito Básico com granada & Coroas & 768 & 759 & 715 & 725 & 667 \\
\hline Granulito Básico com granada & Lamelas & 781 & 817 & 790 & 870 & 785 \\
\hline Granulito Básico com granada & Lamelas & 800 & 837 & & & \\
\hline Granulito Básico c/opaco-granada & Lamelas & 780 & 823 & & & \\
\hline Granulito Básico c/opaco-granada & Coroas & 749 & 777 & & & \\
\hline Granulito Básico c/opaco-granada & Coroas & 750 & 778 & & & \\
\hline Granulito Básico c/opaco-granada & Lamelas & 798 & 837 & & & \\
\hline Granulito Básico c/opaco-granada & Coroas & 701 & 708 & 693 & 723 & 636 \\
\hline
\end{tabular}

Dados geotermométricos Nos estudos geotermométricos foram utilizadas sobretudo duplas de Opx-Cpx em equilíbrio, as quais foram reagrupadas em três tipos principais: (i) relíquias de piroxênios plutônicos; (ii) piroxênios tipomorfos equilibrados no pico do metamorfismo granulítico; e (iii) piroxênios com lamelas de exsolução ou aqueles contornados por coroas simplectíticas de granada mais quartzo, sendo considerados como desestabilizados parcialmente durante o metamorfismo regressivo sob condições da fácies granulito e anfibplito. Os piroxênios considerados relíquias plutônicas (tipo i) são encontrados em rochas que mostram características macroscópicas, claramente plutônicas, com clastos de mesopertita ou plagioclásio, ortopiroxênio e clinopiroxênio dispersos em uma matriz mais fina, onde dominam esses mesmos minerais; contudo, sendo da variedade tipomórfica. Ao microscópio, os piroxênios, relíquias plutônicas, exibem numerosas e bem formadas lamelas de exsolução, são às vezes zonados, verificando-se variações nos teores de ferro, cálcio e magnésio, dos seus centros para as periferias. Os piroxênios tipomorfos (tipo ii) são menores que os anteriores, em geral granoblásticos, e raramente exibem lamelas de exsolução. Em determinadas regiões esses últimos encontram- 
se com tênues lamelas de exsolução e são rodeados por simplectitos de granada mais quartzo (tipo iii), função de reação regressiva, originada por queda da temperatura do metamorfismo. Resultados de análises químicas desses tipos de duplas de piroxênios são encontrados em Barbosa \& Fonteilles (1986) e Barbosa (1986,1989 e 1990). Neles verifica-se que os teores de $\mathrm{Al}_{2} \mathrm{O}_{3}$, nos ortopiroxênios clinopiroxênios das rochas da região são relativamente baixos, em torno de $0,60 \%$ e $1,20 \%$, nã̃o aumentando substancialmente os valores encontrados com os geotermômetros, como, por exemplo, aquele de Wood \& Banno (1973). Este fato poderia ocorrer se nas duplas de Opx-Cpx valores de alumínio anomalamente altos fossem encontrados (Bello et al. 1988).

Para as estimativas das temperaturas metamórficas, foram utilizados sobretudo os métodos de Wood \& Banno (1973) e Wells (1977), embora tenham sido usados também os termômetros de Ellis \& Green (1979), Ganguly (1979) e Krogh (1988). Como pode ser verificado na tabela 3, os piroxênios relíquias (tipo i), encontrados nas partes menos deformadas das rochas plutônicas, apontaram nos seus centros temperaturas variáveis entre $890^{\circ} \mathrm{C}$ e $990^{\circ} \mathrm{C}$. Os piroxênios tipomorfos (tipo ii), na sua maioria em contatos retos ou poligonais com as fases vizinhas, apontaram temperaturas variáveis entre $810^{\circ} \mathrm{C}$ e $900^{\circ} \mathrm{C}$, e finalmente, os piroxênios considerados retrógrados (tipo iii), apontaram valores entre $700^{\circ} \mathrm{C}$ e $820^{\circ} \mathrm{C}$.

Dados geobarométricos As estimativas da pressão do metamorfismo, as mais confiáveis, foram realizadas com as associações Gt-Opx, Gt-Opx-Plag e Plag-Cpx concentradas em granulitos básicos portadores de granada, em quartzitos granatíferos, kinzigitos e em raras amostras de neossoma charnockítico. Para o cálculo dessas pressões sólidas, foram utilizados os métodos de Wood \& Banno (1973), Wood (1974), Wells (1979), Ellis (1980), Newton \& Haselton (1981), Newton \& Perkins (1982) e Harley (1984).

A tabela 4 mostra as fórmulas termodinâmicas utilizadas para o cálculo das pressões do metamorfismo, e os valores encontrados. Como discutido em Barbosa \& Fonteilles (1986) e Barbosa (1988), considerou-se somente os valores obtidos com os métodos de Ellis (1980), Newton \& Perkins (1982) e Harley (1984) que são, no conjunto, mais homogêneos, variando numa faixa relativamente estreita, entre 6 e $7 \mathrm{kbar}$, permitindo classificar o evento granulítico como de pressão intermediária.

CONCLUSÕES A maioria dos pares ortopiroxênio-clinopiroxênio, tanto de rochas do Domínio NW como do Domínio $\mathrm{SE}$, possuem valores de $\mathrm{Kd}$ do $\mathrm{Mg}$ próximos de cerca de 0,56 . Isto reflete as condições físico-químicas uniformes do metamorfismo, sugerindo fortemente que o metamorfismo granulítico progressivo, quando atingiu o seu clímax, reequilibrou na fácies granulito a maioria das rochas da região.

Estimativas geobarométricas baseadas em pares de OpxCpx e Gt-Cpx indicam que a temperatura máxima da fácies granulito progressiva alcançou $830^{\mathrm{t}} 850^{\circ} \mathrm{C}$, ficando preservadas fases reliquiares de Opx-Cpx em rochas plutônicas. Estas fases exibem temperaturas que variam entre 900 e $1.000^{\circ} \mathrm{C}$. A fácies granulito regressiva parece que ocorreu em cerca de $800^{\circ} \mathrm{C}$, como estimado nas lamelas de exsolução em cristais de piroxênio. Temperaturas variando entre $650^{\circ} \mathrm{C}$ e $740^{\circ} \mathrm{C}$ são inferiores àquelas do domínio granulítico, sendo, portanto, considerados aqui como da fácies anfibolito regressiva. Estas últimas foram estimadas em simplectitos de Gt-Cpx encontrados em coroas ao redor de piroxênios dos granulitos básicos ricos em opacos.

O diagrama P-T da figura 4 mostra que o evento metamórfico de alto grau que atingiu a região se restringe ao campo de estabilidade da sillimanita determinado por Richardson et al (1969) e, no domínio da fácies granulito de pressão intermediária estabelecido por Irving (1974). Isto é corroborado pelo fato de a sillimanita ser o único silicato de alumínio encontrado raramente nos kinzigitos e a paragênese Opx-CpxPlag ser a mais comum nos granulitos máficos da região (Barbosa 1990).

As estimativas de temperatura e pressão para as assembléias do metamorfismo progressivo estão colocadas na figura 4 sob a forma de três retângulos que se superpõem em aproximadamente $6 \mathrm{kbar}$ e $830^{\circ} \mathrm{C}$. Os outros dois retângulos, situados à cerca de $4 \mathrm{kbar}$ e $750^{\circ} \mathrm{C}$ e $3 \mathrm{kbar}$ e $720^{\circ} \mathrm{C}$, respectivamente, representam as condições do metamorfismo retrogrado.

Com base na localização dos três retângulos de P-T do metamorfismo progressivo e na existência de migmatitos na região, tanto na fácies anfibolito como na granulito, o melhor posicionamento da curva de fuso do granito e da curva de transição fácies anfibolito-granulito aponta para 0,3 da pressão total como a mais adequada $\mathrm{P}_{\mathrm{H}_{2} \mathrm{O}}$ durante o metamorfismo da área. $\mathrm{P}_{\mathrm{H}_{2} \mathrm{O}}$ mais baixas são conseqüentemente visualizadas para as zonas nãomigmatizadas. Sobre a trajetória do metamorfismo, apesar da presente falta de dados quantitativos adequados da fácies anfibolito, é possível sugerir que,pelo menos para as zonas migmatizadas da fácies anfibolito, a curva de fuso do granito foi alcançada antes da transição anfibolito-granulito, que parece ter ocorrido a cerca de $6,5 \mathrm{kbar}$ e $800^{\circ} \mathrm{C}$. Com o aumento da temperatura progressiva, a curva de transição anfibolito-granulito foi atravessada sendo o pico do metamorfismo alcançado a aproximadamente $7 \mathrm{kbar}$ e $840^{\circ} \mathrm{C}$, após a paralisação das principais fases de deformação dúctil (Barbosa 1986). A migmatização sob condições da fácies anfibolito parece ter ocorrido antes e após o clímax metamórfico. Soerguimento acompanhado por deformação tectônica e decréscimo de T conduziu à estabilização de assembléias retrógradas (fácies anfibolito e xisto verde) provavelmente ao longo da trajetória do metamorfismo mostrado na figura 4.

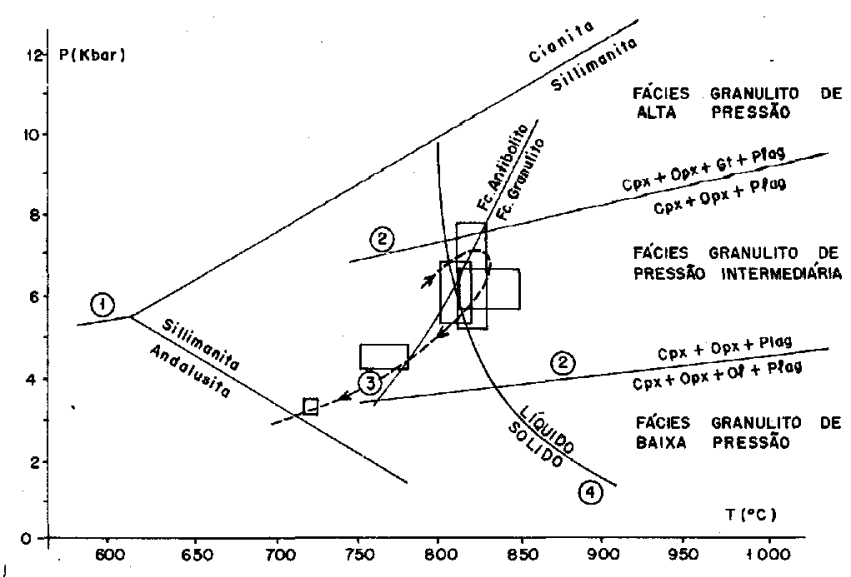

Figura 4 - Diagrama de temperatura e pressão do metamorfismo. 1. limites de estabilidade dos silicatos de alumínio segundo Richardson et al. (1969); 2. limites da fácies granulito segundo Irving (1974); 3. curva da reação de destruição da hornblenda válida para $\mathrm{P}_{\mathrm{H}_{2} \mathrm{O}}=0,3$ Pt (Wells 1979); 4. curva de fuso do granito sob condições $\mathrm{P}_{\mathrm{H}_{2} \mathrm{O}}=0,3$ Pt (Manna \& Sen 1974). Os retângulos representam condições de TeP estimadas para a reação usando amostras e diferentes métodos termobarométrícos (Tab. 3 e 4). A linha tracejada representa a trajetória proposta para o metamorfismo.

Figure 4 - Metamorphic temperature and pressure diagram. 1. stability limits of aluminum silicates according to Richardson et al (1969); 2. limits of the granulite fácies according to Irving (1974); 3. reaction curve of the destruction of hornblende valid for $\mathrm{P}_{\mathrm{H}_{2} \mathrm{O}}=03 \mathrm{Pt}$ (Weels, 1979); 4. fusion curve for granite valid for $\mathrm{P}_{2} \mathrm{O}=03 \mathrm{Pt}$ (Manna \& Sen 1974). The rectangles represent conditions of $\mathrm{T}$ and $\mathrm{P}$ estimated for the study area wing samples and different thermobarometric methods (Tab. 3 and 4). The broken line represents the path proposed for metamorphism 
Tabela 4 - Pressões (kbar) metamórficas de rochas da região granulitica do Sul da Bahia

Table 4 - Metamorphic pressures (kbar) of the Southern Bahia granulitic region rocks

\begin{tabular}{l|c|c|c|c|c|c|c}
\hline ROCHAS & $\begin{array}{c}\text { WOOD \& } \\
\text { BANNO } \\
(1973)\end{array}$ & $\begin{array}{c}\text { WOOD } \\
(1974)\end{array}$ & $\begin{array}{c}\text { WELLS } \\
(1979)\end{array}$ & $\begin{array}{c}\text { ELLIS } \\
(1980)\end{array}$ & $\begin{array}{c}\text { NEWTON \& } \\
\text { HASELTON } \\
(1981)\end{array}$ & $\begin{array}{c}\text { NEWTON \& } \\
\text { PERKINS } \\
(1982)\end{array}$ & $\begin{array}{c}\text { HARLEY } \\
(1984)\end{array}$ \\
\hline
\end{tabular}

\section{DOMINIONW}

Kinzigito $\quad 4,8$

\begin{tabular}{|c|c|c|c|c|c|c|}
\hline Quartzito Granatífero & & & 4,7 & & 6,1 & 6,1 \\
\hline QuartzitoGranatifero & $-2,6$ & 4,4 & 4,5 & & 6,2 & \\
\hline Neossoma Charnockítico & & & 5,2 & 5,9 & & 5,7 \\
\hline
\end{tabular}

\section{DOMÍNIOSE}

\begin{tabular}{lllllll} 
Granulito Básico com granada & 5,5 & $(15,5)$ & 5,8 & 8,7 & 6,3 & 6,5 \\
\hline Granulito Básico com granada & 3,0 & $(14,5)$ & 5,2 & $(12,0)$ & 6,7 & 6,8 \\
\hline Granulito Básico com granada & 2,4 & $(14,3)$ & 5,9 & & 7,9 & 6,9 \\
\hline Granulito Básico c/opaco-granada & 4,5 & $(17,7)$ & 3,5 & 7,0 & 3,1 & 3,5 \\
\hline Granulito Básico c/opaco-granada & 3,6 & $(17,1)$ & 4,7 & 6,0 & 6,4 & \\
\hline Granulito Básico c/opaco-granada & 2,5 & $(19,6)$ & 3,8 & 6,8 & 4,6 & \\
\hline
\end{tabular}

Obs.: Os resultados entre parênteses são duvidosos

- WOOD A BANNO (1973)

$\mathrm{P}=1+\frac{\frac{\mathrm{RTln}\left(\mathrm{X}_{\mathrm{Mg}}^{\mathrm{M}_{1}, \mathrm{Opx}}\right)\left(\mathrm{X}_{\mathrm{Mg}}^{\mathrm{M}_{2}, \mathrm{Opx}}\right)^{2}\left(\mathrm{X}_{\mathrm{Al}}^{\mathrm{M}_{1}, \mathrm{Opx}}\right)+4,207-2,69 \mathrm{~T}}{\left(\mathrm{X}_{\mathrm{Mg}}^{\mathrm{Gt}}\right)^{3}}}{\Delta \mathrm{V}}$

\section{-WOOD (1974)}

$\mathrm{P}=\frac{\mathrm{RT}}{\Delta \mathrm{V}} \ln \frac{\left(\mathrm{X}_{\mathrm{Al}}^{\mathrm{M}_{1}}\right)\left(1-\mathrm{X}_{\mathrm{Al}}^{\mathrm{M}_{1}}\right)}{\left(1-\mathrm{X}_{\mathrm{Gr}}^{\mathrm{Gt}}\right)^{3}}+\frac{7,012-3,89 \mathrm{~T}-\mathrm{C}\left(\mathrm{X}_{\mathrm{Fe}}^{\mathrm{Opx}}\right)\left(1-2 \mathrm{X}_{\mathrm{Al}}^{\mathrm{M}_{1}}\right)}{\Delta \mathrm{V}}$

\section{- WELLS (1979)}

$\mathrm{P}=1+\frac{3,300+6,26 \mathrm{~T}+\mathrm{RT} \operatorname{In} \mathrm{K}_{\mathrm{A}}}{0,56771}$

\section{-ELLIS (1980)}

$\mathrm{P}=\frac{5,360+\mathrm{T}(2,98+1,98 \ln \mathrm{K})+12,86 \mathrm{X}_{\mathrm{CaTs}}(1-\mathrm{CaTs})-26,88\left[\mathrm{X}_{\mathrm{CaTs}}\left(1-\mathrm{X}_{\mathrm{CaTs}}\right)\right]^{2}-\mathrm{X}_{\mathrm{Ab}} \mathrm{X}_{\mathrm{An}}\left[967+715\left(\mathrm{X}_{\mathrm{Ab}} \mathrm{X}_{\mathrm{An}}\right)\right]}{0,349}$

\section{- NEWTON \& PERKINS (1982)}

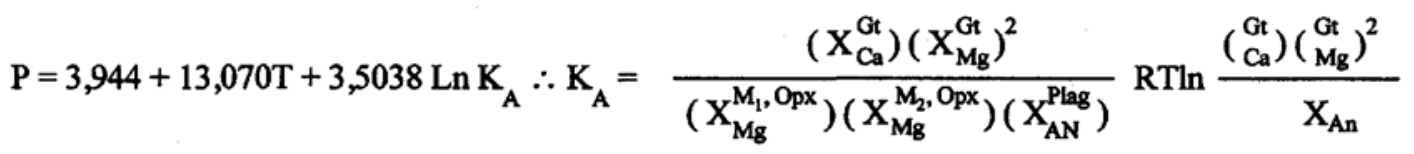

Como pôde ser verificado neste trabalho e em Barbosa $(1986,1989,1990$ e 1991), a maioria dos dados conduzem para a interpretação de que o metamorfismo retrógrado identificado ocorreu quando do levantamento deste segmento crustal. Este foi acompanhado do decréscimo de temperatura seguido de deformações tectônicas, o que permitiu a estabilização de 
assembléias retrógradas $(\mathrm{Kd}=0,50$, Fig.2) em rochas antes portadoras de ortopiroxênio, formadas no pico do metamorfismo $(\mathrm{Kd}=0,56$, Fig. 2), caracterizando um só evento metamórfico na região. Contudo, não é descartada a possibilidade dessas assembléias retrógradas terem sido produzidas por um novo evento metamórfico da fácies anfibolito, que se superpôs ao da fácies granulito, mais antigo. A propósito, estão sendo encontrados ao norte da região granulítica em estudo, com paragênese da fácies anfibolito, rochas sieníticas com idades $\mathrm{Rb} / \mathrm{Sr}$ em torno de 1,9 $\mathrm{Ga}$, deformadas do mesmo modo que as rochas granulíticas encaixantes, estas últimas retrogradadas para a fácies anfibolito. Estes fatos podem indicar, embora preliminarmente, a existência de dois ciclos geotectônicos na área. Trabalhos de datações geocronológicas, com a utilização de vários métodos radiométricos superpostos, estão sendo empreendidos para verificar esta possibilidade.

Agradecimentos Os autores agradecem ao Conselho Nacional de Desenvolvimento Científico e Tecnológico (CNPq) e à Superintendência de Geologia e Recursos Minerais da Secretaria das Minas e Energia (SGM/SME), pelo financiamento destas pesquisas. Também formulam agradecimentos à Université Pierre et Marie Curie-Paris VI que possibilitou a realização de análises químicas de fases minerais em microssonda eletrônica. Finalmente, são gratos aos colegas Leo A. Hartmann da Universidade Federal do Rio Grande do Sul e Maria da Glória da Silva da Universidade Federal da Bahia, pelas valiosas sugestões que deram quando da leitura final do texto.

\section{REFERÊNCIAS BIBLIOGRÁFICAS}

ARCANJO, J.BA.; BARBOSA, J.S.F.; OLIVEIRA, J.F. 1992. Caracterização petrográfíca e metamórfica dos granulitos arqueanos/proterozóicos inferior da região de Itabuna (BA). Rev. Bras. Geoc., (no prelo).

BARBOSA, J.S.F. 1986. Constitution Lithologique et Metamorphique de Ia Region Granulitiqtte du Sudde Bahia-Brésil. França. 402 p. (Tese de Doutoramento, Université Paris VI).

BARBOSA, J.S.F. 1988. Principais geobarômetros utilizados em granulitos: análise dos resultados de um exemplo do sul da Bahia - Brasil. Rev. Bras. Geoc.,18(2):162-169.

BARBOSA, J.S.F. 1989. Química mineral utilizada na identificação das fácies metamórficas da região granulítica do sul da Bahia, Brasil. Rev. Bras. Geoc., 19(3):350-366.

BARBOSA, J.S.F. 1990. The granulites of the Jequié Complex and Atlantic Mobile Belt, Southern Bahia, Brazil-An Expression of Archean Proterozoic Plate Convergence. In: VIELZEUF, D. \& VIDAL, Ph. ed Granulites and Crustal Evolution. Amsterdam, Springer Verlag. 585 p.

BARBOSA, J.S.F. 1991. Projeto Geologia e Metalogenia do Domínio da Costa Atlântica da Região Granulítica do Sul da Bahia. Salvador, Convênio SME/SGM/UFBa. (Rei. Final).

BARBOSA, J.S.F \& FONTEILLES, M. 1986. Examen critique des resultats foumis par certains barométres couramment utilises en terrain granulitiques. Exemples des granulites de Bahia (Brésil) et du Massif de 1'Agly (France). Bull. Mineral. 109:359-376.

BELLO, R.M.S.; VALARELLI, J.V.; GUTTLER, R.S. 1988. Correções de temperaturas obtidas pelo método de Wood \& Banno para fases de piroxênios ricos em $\mathrm{Al}_{2} \mathrm{O}_{3}$ de Surubim (BA). Rev. Bras. Geoc., 18(3):328-331.

BELLO, R.M.S.; VALARELLI, J.V.; RUBERTI, E. 1988. Geotermometria geobarometria dos granulitos de Surubim, BA. An. Acad. bras. Cien. 60(2):207-221

BHATTACHARYA, C. 1971. An evaluation of the chemical distinctions between igneous and metamorphic orthopyroxenes. Am. Mineral., 56:499-506.

BINNS, R.A. 1962. Metamorphic pyroxenes from the Broken Hill District, New South Wales. Mineral. Magaz., 33:320-338.

BRITO-NEVES.B.B.; CORDANI.U.G.; TORQUATO, J.R.F. 1980. Evolução geocronológica do precambriano do Estado da Bahia. In: Geologia e Recursos Minerais do Estado da Bahia. Salvador, SME/SGM. p. 1-101. (Textos Básicos 3)

CONVERT, J. 1981. Lês Granulites a Orthopiroxenes de Laponie (Finlande et Norvege). Pétrologie et Géochimie. França. 181 p. (Tese de LivreDocência, Université Rennes 1).

COOLEN, M.M.M.J.J. 1980. Chemical Petrology of Furua Granulite Complex, Southern Tanzânia. Gua. Papers of Geology, série $1, \mathrm{n}^{\circ} 13$

CORDANI.U.G. 1973. Evolução Geológica Precambriana da Faixa Costeira do Brasil, entre Salvador e Vitória. São Paulo. 80 p. (Tese de LivreDocência, IG/USP)

CORDANI, U.G. \& IYER, S.S. 1979. Geocronological investigation on the precambrian granulite terrain of Bahia, Brazil. Precamb. Res., 9:255-274

COSTA, L.A.M. \& MASCARENHAS, J.F. 1982. The high-grade metamorphic terrains in the interval Mutuipe-Jequié: Archean and Lower Proterozoic of east-central Bahia In INTERNATIONAL SYMPOSIUM ON ARCHEAN AND EARLY PROTEROZOIC GEOLOGIC EVOLUTION METALLOGENESIS. Salvador, 1982. Proceedings.. Salvador, p. 19-37.

CRUZ, M.J. 1989. Le Massif de Rio Piau: Une Intrusion de Nature Gabroique etAnorthositiquedans les Terrains Granulitiques du Noyau Jequié, Bahia Brésil. França. 257 p. (Tese de Doutoramento, Université Paris IV).

DAVIDSON, L.R. 1968. Variations in ferrours Iron-Magnesium distribution coefficients of metamorphic pyroxenes from Quairading, Western Australia. Contr. Mineral. Petrol., 19: 239-259.

DELHAL, J. \& DEMAIFFE, D. 1985. U-Pb Archean geochronology of the São Francisco Craton (Eastern Brazil). Rev. Bras. Geoc., 15:55-60.
ELLIS, D.J. 1980. Osumilite-Sapphirine-Quartz Granulites from Enderby Land, Antarctica: P-T conditions of metamorphism, implications for Garnet-Cordierite equilibria and the evolution of the Deep Crust. Contrib. Mineral. Petrol., 74:201-210.

ELLIS, D.J. \& GREEN, D.H. 1979. An experimental study on the effect of Ca upon gamet-clinopyroxene $\mathrm{Fe}-\mathrm{Mg}$ exchange equilibria. Contrib. Mineral. Petrol., 71:13-23

ELLIS, D.J. \& GREEN, D.H. 1985. Garnet forming reactions in mafic granulites from Enderby Land, Antarctica-Implications for geothermometry and geobarometry. J. Petrol., 26:633-662.

GANGULY, J. 1979. Garnet and clinopyroxene solid solution, and geothermometry based on Fe-Mg distribution coefficient. Geochim. Cosmochimica Acta, 43:1021-1029.

GREEN, D.H. \& RINGWOOD, A.E. 1967. An experimental investigation of the gabbro-eclogite transformation and its petrological applications. $G e$ ochim. Cosmochim. Acta, 31:767-838.

HARLEY, S.L. 1984. An experimental study of the partitioning of Fe and $\mathrm{Mg}$ between garnet and orthopyroxene. Contrib. Mineral. Petrol., 86:359-373

IRVING, A.J. 1974. Geochemical and high pressure experimental studies of garnet pyroxenite and pyroxene granulite xenoliths from the delegate basaltic pipes. Australia, J. Petrol., 15:1-40.

IYER, S.S · CHOUDHURI, LA ; CORDANI, U.G. 1987. Granulite fades rocks of Brazil: a review of their geologic setting, geochronological evolution, petrographic and geochemical characteristics. J. Geol. Soc. India, 29:309-326.

KRETZ, R. 1961. Some explications of thermodynamics to coexisting minerals of variable composition. Exemples: ortopyroxene clinopyroxene and orthopyroxene - garnet. J. Geol., 69:361-387.

KRETZ, R. 1963. Distribution of magnesium and iron between orthopyroxene and calcic pyroxene in natural mineral assemblages. J. Geol., 71:773785

KROGH, E.J. 1988. The garnet - clinopyroxene Fe-Mg geothermometer - a reinterpretation of existing experimental data. Contr. Mineral. Petrol., 99:44-48.

LIMA, M.I.C.; FONSECA, E.G.; ELSON, P.O.; GHIGNONE, J.I.; ROCHA, R.M.; CARMO, U.F C.; SILVA, JM.R.; SIGA, O., Jr. 1982. In: RADAMBRASIL. Levantamento de Recursos Naturais, Folha SD-24 Salvador. Rio de Janeiro, Projeto Radambrasil. 620 p. (Relatório 24).

LOOMIS, T.P. 1977. Kinetics of a garnet granulite reaction: Contrib. Mineral. Petrol., 62:1-22.

MANNA, S.S. \& SEN, S.K. 1974. Origin of garnet in the basic granulites around Saltora, W. Bengal. India. Contrib. Mineral. Petrol., 44:95-218

MASCARENHAS, J.F. 1979. Evolução geotectônica do precambriano do Estado da Bahia. Geologia e Recursos Minerais do Estado da Bahia. Salvador, SME/CPM. p. 57-165. (Textos Básicos 2).

MIRANDA, LIF ; SOARES, S.V ; CRUZ, MJM ; MORAIS, A.MV. 1985. SME/CBPM. - Projeto Ubaira-Santa Inês. Salvador, SME/CBPM. (Rei. Final 1).

MIRANDA, L.L.F.; SOARES, J.V.; MORAES, A.M.V. 1982. Geologia da Região de Ubaira-Santa Inês. In: CONOR. BRAS. GEOL., 32. Salvador, 1982. Anais... Salvador, SBG. v. 1, p. 246-259.

NEWTON, R.C. \& HASELTON, H.T. 1981. Thermodinamics of the garnet plagioclase - $\mathrm{Al}_{2} \mathrm{SiO}_{4}$ - qt-artz geothermometer. In: NEWTON, R.C.; NAVROTSKY, A.; WOOD, B.J. ed. Thermodynamics of Mineral and Melts. Amsterdam, Springer-Verlag. p. 129-145.

NEWTON, R.C. \& PERKINS, D., HI. 1982. Thermodynamic calibration of geobarometer based on the assemblages garnet - plagioclase ortopyroxene (clinopyroxene) - quartz. Am. Mineral., 67:203-222.

OLIVEIRA, E.P. \& LIMA, M.I.C. 1982. Aspectos petrográficos das rochas granulíticas do Complexo Jequié e estimativas das condições físicas do metamorfismo. In: CONGR. BRÁS. GEOL,32. Salvador, 1982. Anais. Salvador, SBG. v.2, p. 589-602. 
OLIVEIRA, E.P.; LIMA, M.I.C.; CARMO, U.F.; WERNICK, E. 1982. The Archean granulite terrain from east, Brazil. Rev. Bras. Geoc., 12(1-3):356-368

RICHARDSON, S.W.; GILBERT, M.C.; BELL, P.M. 1969. Experimental determination of the Kyanite-andalusite and andalusite-sillimanite equilibria; the aluminium silicate triple point. Am. J. Set., 267:259-272.

SAMPAIO, H.A. 1988. Mapa Metamórfico do Estado da Bahia - Folha Jequié: 1:250.000. Salvador, SGM/SME. (Publ. Especial).

SEIXAS, S.R.M.; MARINHO, M.M.; MORAES, P.O.; AWDZIES, J.; SAMPAIO, A.R.; PEDROSA, C.S.; SANTOS, D.A.; PEDREIRA, S.G.V.V. 1975. Projeto Bahia II. Relatório Final. Geóloga da Bacia do Rio de Contas. DNPM/CPRM. 230 p. (Vol. 3).

SEN, S.K. \& RAY, S. 1971. Breakdown reactions for natural hornblendes in granulite fades. N. Jb Mineral. Abh., 114:301-319.

SIGffINOLFI, G.P. 1970. Investigation into the deep levels of the continental crust: petrology and chemistry of the granulite fades terrains of Bahia (Brazil). AM. Soe. Tose. Sci. Nat. Mem., 77:327-341.

SIGHINOLFI, G.P. 1971. Investigation into the deep crustal levels: fractionacting effects and geochemical trends related to high-grade metamorphism. Geochim. Cosmochim. Acta, 35:1005-1021.

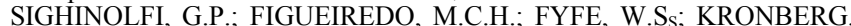
B.I.; OLIVEIRA, M.A.F. de. 1981. Geochemistry and petrology of the Jequié Granulite Complex (Brazil): an archean basement complex. Contrib. Mineral. Petrol, 78:263-271.

SIGHINOLFI, G.P. \& SAKAI, T. 1977. Uranium and Thorium in archean granulite fades terrains of Bahia (Brazil). Geoch. J., 11:33-39.

TONIATTI, G. \& BARBOSA, J.S.F. 1973. O manganês de Maraú-Bahia, Avaliação de Reservas. In: CONGR. BRAS. GEOL, 27. Sergipe, 1973. Anais... Sergipe, SBG. v. 2. p. 121-430.

VALARELLI, J.V.; BARBOSA, J.S.F.; HYPOLITO, R.; BELLO, SJLM. 1982. Paragênese do protominério metamórfico de manganês de Maraú, Bahia. In: CONGR. BRÁS. GEOL., 32. Salvador, 1982. Anais... Salvador, SBG. v. 3, p. 819-835.
XAVIER, R.P.; BARBOSA, J.S.F.; IYER, S.S.; CHOUDHURI, A.; VALARELLI, J.V.;CORDANI,U.G. 1989. Low density carbonic fluids in the archean granulite fácies terrain of the Jequié Complex, Bahia, Brazil. $J$. Geol., 97:351-359.

WAGNER, M.E. \& CRAWFORD, M.L. 1975. Polymetamorphism of the Precambrian Baltimore gneiss in northeastern Pensylvania. Amer. J. Sci., 275:653-682.

WELLS, P.R.A. 1977. Pyroxene thermometry in simple and complex systems. Contrib. Mineral. Petrol., 62:129-139.

WELLS, P.R.A. 1979. Chemical and thermal evolution of Archean sialic crust, Southern West Greenland. J. Petrol., 20:187-226.

WILSON, N. 1987. Combined Sm-Nd, $\mathrm{Pb} / \mathrm{Pb}$ and $\mathrm{RbASr}$ geochronology and isotope geochemistry in polimetamorphic Precambrian terrains: examples from Bahia, Brazil and Channel Island, U.K. Inglaterra. 151 p. (Dissertação de Mestrado, Oxford University).

WILSON, N.; MOORBATH, S.; TAYLOR, P.N.; BARBOSA, J.S.F. 1988 Archean and early proterozoic crustal evolution in the São Francisco Craton, Bahia,Brazil. Chem. Geol., 70(1-2): 146.

WINKLER, H.G.F. 1977. Petrogenesis of Metamorphic Rocks. 1 ed. Amsterdam, Springer-Verlag. 334 p.

WOOD, B.J. 1974. The solubility of alumina in orthopyroxene coexisting with garnet. Contrib. Mineral. Petrol., 46:1-15.

WOOD, B.J. \& BANNO, S. 1973. Garnet - ortopyroxene and ortopyroxene clinopyroxene relationship in simple and complex systems. Contrib. Mineral. Petrol., 42:109-124.

MANUSCRITO A697

Recebido em 27 de marco de 1991

Revisto do autor em 13 de novembro de 1991 Revisto aceita em 2 de dezembro de 1991 